NBER WORKING PAPER SERIES

\title{
ESTIMATING THE ECONOMIC VALUE OF ZONING REFORM
}

\author{
Santosh Anagol \\ Fernando V. Ferreira \\ Jonah M. Rexer \\ Working Paper 29440 \\ http://www.nber.org/papers/w29440 \\ NATIONAL BUREAU OF ECONOMIC RESEARCH \\ 1050 Massachusetts Avenue \\ Cambridge, MA 02138 \\ October 2021, Revised March 2023
}

We are grateful for support from the Wharton Dean's Research Fund, and the Research Sponsors Program of the Zell/Lurie Real Estate Center. We thank Tom Cui, Anna Gao, Lucas Fernandes, Gi Kim, Renan Muta, Sophia Winston, Alexandru Zanca, and Holly Zhang for excellent research assistance. We also thank Rohan Ganduri, Edward Glaeser, Joseph Gyourko, Raven Molloy, and seminar participants at Imperial College Business School, Wharton Urban Lunch, European Urban Economics Association meeting, American Urban Economics Association meeting, NBER Summer Institute Real Estate, FGV-SP, Brazilian Society of Econometrics, LACEA-LAMES, NBER Public Economics, NTA meeting, Biennial Atlanta-Dallas Fed Conference, and the SITE conference at Stanford for helpful comments and suggestions. Finally, we thank Danilo Igliori and the DataZap team for providing the real estate listing data used in this research. The views expressed herein are those of the authors and do not necessarily reflect the views of the National Bureau of Economic Research.

At least one co-author has disclosed additional relationships of potential relevance for this research. Further information is available online at http://www.nber.org/papers/w29440

NBER working papers are circulated for discussion and comment purposes. They have not been peer-reviewed or been subject to the review by the NBER Board of Directors that accompanies official NBER publications.

(C) 2021 by Santosh Anagol, Fernando V. Ferreira, and Jonah M. Rexer. All rights reserved. Short sections of text, not to exceed two paragraphs, may be quoted without explicit permission provided that full credit, including ( $)$ notice, is given to the source. 
Estimating the Economic Value of Zoning Reform

Santosh Anagol, Fernando V. Ferreira, and Jonah M. Rexer

NBER Working Paper No. 29440

October 2021, Revised March 2023

JEL No. H0,O18,R0

\begin{abstract}
$\underline{\text { ABSTRACT }}$
We develop a framework to estimate the economic value of a recent zoning reform in the city of São Paulo, which altered maximum permitted construction at the city-block level. Using a spatial regression discontinuity design, we show that developers respond to the reform with short-run increases in filings for multi-family construction permits in blocks with higher allowable densities. In the medium-run we observe increases in housing availability and reductions in house prices in neighborhoods that were allowed more densification. Welfare is then estimated with an equilibrium model of housing demand and supply that allows for endogeneous housing regulation. We finding that, in the long-run, the reform produces a $1.9 \%$ increase in housing stock and a $0.5 \%$ reduction in prices, with substantial heterogeneity across neighborhoods. Consumer welfare gains due to price reductions are small, but increase 4-fold once accounting for changes in built environment, with more gains accruing to college educated and higher income families. However, nominal house price losses faced by landlords and existing homeowners overshadow all consumer welfare gains.
\end{abstract}

Santosh Anagol

University of Pennsylvania

3733 Spruce Street

Vance Hall 321

Philadelphia, PA 19146

anagol@wharton.upenn.edu

Fernando V. Ferreira

Wharton Real Estate

University of Pennsylvania

430 Vance Hall

3733 Spruce Street

Philadelphia, PA 19104-6301

and NBER

fferreir@wharton.upenn.edu
Jonah M. Rexer

322 Bendheim Hall

School for Public and International Affairs

Princeton University

Princeton, NJ 08544

jrexer@princeton.edu

A data appendix is available at http://www.nber.org/data-appendix/w29440 


\section{Introduction}

The global urban population has been steadily increasing, from 33\% in 1960 to $56 \%$ in 2019, with a predicted increase to $68 \%$ by 205011 However, there is considerable uncertainty and debate regarding the ability of cities to provide adequate housing for their residents in the future. Satisfying the demand to live and work in cities will only be possible with a strong supply response from developers who build residential structures. In most cities, however, the supply of buildings is highly regulated by local authorities - the so-called "not in my back yard" NIMBYism - who can legally determine if and how developers can build (Glaeser, Gyourko and Saks, 2005; Gyourko and Molloy, 2015; Gyourko, Hartley and Krimmel, 2021).

Researchers attempting to assess the impact of zoning policies face four major challenges. First, zoning policies are often endogenous, determined by price levels (e.g. high price areas choosing to restrict building to maintain high prices) - so comparisons across different jurisdictions can plausibly conflate price effects with zoning reform effects. Second, zoning policies are multi-dimensional and difficult to measure and compare across time and locations; for example cities can regulate land use, building density, lot size, height, footprint, and setbacks, among other characteristics ${ }^{2}$ Third, there is a dearth of micro data on the behavior of developers, which is critical to estimating supply responses to local land use regulations. Fourth, even when these three challenges are solved, it is difficult to trace out the impacts of zoning on built environments, price affordability, and welfare given the many aspects of supply and demand for housing impacted by local regulation. For example, new housing construction may improve the quality of the housing stock relative to the old and depreciated stock of homes, reduce housing prices, and allow households to move from the suburbs to the city and closer to their workplaces. But densification may also lead to increases in congestion, construction of less desirable apartment units (as opposed to single family housing), and loss of housing wealth by current homeowners and landlords, which is sometimes feared by proponents of NIMBYism.

Our paper shows how zoning reform and detailed data can be leveraged to address these four challenges. We study a major reform in São Paulo, Brazil that generated granular, block-by-block changes in zoning parameters. The setting allows for a within-city approach that exploits both variation over time in zoning policy changes and block-level discontinuities in reform parame-

\footnotetext{
1 United Nations Population Division. World Urbanization Prospects: 2018 Revision.

2 The highly used Wharton Land Use Regulation Index (WLURI) is a summary measure of many land use restrictions collected via survey data. While WLURI is a useful proxy for overall land use regulation, it is difficult to translate causal effects of this index in to specific administrative land use parameters that might actually be reformed.
} 
ters. We collect detailed administrative data to observe exactly which zoning parameters change and how these changes impact housing supply across the city at fine spatial resolution. By combining a reform with data on permitting activity and housing listings, we can credibly estimate the short-run responses of developers when land-use restrictions change, and the medium-run changes in housing supply and listing prices. Finally, we estimate an equilibrium model of housing supply and neighborhood demand to separately identify how changes in prices, quantities, and neighborhood amenities affect household welfare.

We examine the impact of a 2016 zoning reform in São Paulo, Brazil - the world's 4th largest metropolitan area with 21 million residents. The block-level reform centralized the ability to set density parameters previously under control of neighborhoods, and had the general goal of providing more dignified housing for its residents and allowing more densification along transportation corridors $\mathrm{S}^{3}$ Each city block was assigned a maximum built-area-ratio (BAR) - the ratio of constructed square meters per square meter of land area - which defines the density of units that developers could develop on a given land parcel $4^{4}$ On average, the max BAR in the city's approximately 45,000 blocks increased from 1.54 to 2.09 , allowing $36 \%$ more construction for a given lot size, and $45 \%$ of the city blocks had a max BAR increase of 1 or more $5^{5}$ This unique variation in zoning restrictions over space and time allows us to control more precisely for the endogenous determinants of zoning policies.

We use a boundary discontinuity design to estimate developers' supply response to blocklevel changes in BAR. Blocks are categorized as treatment (where max BAR increased) or control (where max BAR stayed constant or decreased), and our running variable is the distance to the nearest block of the opposite category. Our identification exploits both cross-sectional and temporal changes in zoning regulation at the boundary discontinuity (in the spirit of a "differencein-discontinuities" design). Balance tests suggest that the typical endogenous determinants of zoning policy, such as prices and density, are indeed balanced at the cut-off.

\footnotetext{
3 The São Paulo reform's focus on increasing housing density near transportation corridors is similar to a recently failed reform aiming to increase housing density along California's public transit system (Dougherty. 2020). Mumbai's 2034 development plan also originally included, but then removed, plans for allowing high density construction near metro and commuter rail stations (Ashar. 2018).

4 We use the term BAR as it corresponds directly with term used in Sao Paulo for this concept. It is closely related to the "FAR" ("floor-to-area"), "FSI" ("floor-space index") and "FSR" ("floor-space-ratio") metrics used in other parts of the world. See Brueckner and Singh (2020) for recent measurements for "FAR" stringency in five major U.S. cities. Sao Paulo has a unique set of rules defining what counts as constructed area; it includes livable space but excludes hallways, elevator shafts and in some cases mezzanine lobbies and swimming pools. Given these idiosyncracies we prefer to use the "BAR" terminology.

5 See Tabarrok and Cowen (2018) for a discussion of the floor space index parameter in India, similar to the BAR parameter, and its importance in determining housing availability in Mumbai.
} 
We first apply this research design to rich administrative microdata on building permits. We find that the 1.4-point max BAR increase at the cut-off causes an increase of .003 multi-family dwelling permits filed per block per quarter, which is a sixty six percent increase in permits per unit of max BAR in treated relative to nearby control blocks. The differences in permiting activity between treatment and control blocks emerge just one year after the zoning reform was passed and increase thereafter, which is plausible given the time it likely takes for developers to create project plans, acquire land, and so on. We find no effect of a max BAR increase on single-family home permits filed or approved, which is consistent with the zoning parameter change easing constraints primarily for larger structures. We also estimate a spatial spillover model (following a strategy similar to Diamond and McQuade (2019)), finding no evidence of treatment effects on control blocks near the boundary discontinuity, suggesting minimal substitution of projects from control to treatment blocks. We find similar sized effects for treatment blocks near and far from the boundary, suggesting muted agglomeration effects so far. We also find the reform had negligible consequences for the development of commercial structures.

We also estimate medium-run reform effects on housing market outcomes six years after the reform was enacted. For this exercise we use data from DataZap, a private Brazilian website similar to Zillow, that provides complete listings of apartments and houses for sale and their prices. We find that total housing units for sale increase by 10 percent in blocks that allow for more densification. The border discontinuity design, however, cannot assess price effects of zoning reforms since neighborhood amenities are generally not segmented by block. 6 We instead study neighborhood-level effects by aggregating availability of houses for sale and listing prices at the commuting zone level, which are cohesive neighborhoods with on average roughly 10,000 households. We find that neighborhoods with larger positive changes in max BAR have more growth in housing supply, and the effect is quantitatively similar to the block level boundary estimates. That same increase in max BAR results in listing price declines, indicating that the supply impact on prices dominates any price gains from improved amenities due to densification.7

We then estimate an equilibrium model of supply and demand to predict the welfare consequences of the Sao Paulo 2016 reform. Our supply model extends the reduced form approach by

\footnotetext{
6 In particular, Turner, Haughwout and Van Der Klaauw (2014) show that boundary discontinuity designs alone (including ours), cannot identify price, congestion and broader welfare effects which we would expect to affect both sides around a border experiencing a zoning change.

7 One caveat with these estimates is that Brazil also suffered the health and economic consequences of the COVID-19 pandemic, and it is difficult to empirically isolate how the reform would have impacted listings and price differentials by 2022 in the absence of the pandemic. In our model below, however, we are able to estimate long-run simulations in the absence of COVID-19.
} 
adding the impact of prices, neighborhood features, and other regulatory zoning constraints. We estimate this model at the neighborhood level using Poisson regression to avoid the problem introduced by log-linear models when many locations have zero permits. Prices and max BAR are both endogenous. We instrument for BAR constraints using the boundary discontinuity-based variation, while at the same time controlling for other regulations, such as rules limiting the size of a building's footprint (the "shadow ratio"), minimum setbacks, and height limits. We instrument for prices using localized demand-side Bartik shocks as in (Baum-Snow and Han, 2022). We find that a max BAR increase of 1 roughly doubles the number of permits, similar to our block-level boundary discontinuity model. A price increase of $20 \%$ generates a $50 \%$ increase in permits.

On the demand side, individuals maximize utility when choosing neighborhoods as a function of prices, location features, access to employment opportunities, and commuting time, allowing for residents to value both the positive and negative aspects of more densification. To estimate the model, we use survey data on 24,800 São Paulo metropolitan statistical area households which includes information on demographics, place of residence, and place of work. We instrument endogenous listing prices with geographic features in a ring outside the commuting zone; this strategy follows Berry, Levinsohn and Pakes (1995) and rests on the assumption that these outside features impact local prices through competition but do not directly impact the utility of individuals living in a given zone. To estimate consumers' preference for access to high paying jobs, we follow Tsivanidis (2022) and define an index of residential commuter access (RCMA) which measures a location's average travel time to zones with high paying jobs. Travel time is also allowed to vary according to neighborhood congestion. Finally, utility is driven by other important neighborhood features, such as age of buildings, number of units per building, neighborhood density, share of households with a paved road, average zone income, and share of zone adults with a college degree. We follow Davis et al. (2021) in assuming exogeneity of neighborhood demographics.

Preferences for all of these neighborhood features are allowed to vary according to an individual's demographic characteristics. We model preferences using a multinomial logit framework and estimate the parameters with a two-stage maximum likelihood procedure, as in Bayer, Ferreira and McMillan (2007). We find negative elasticities of demand with respect to both prices and travel times, and a positive elasticity for RCMA; conditional on price and travel times, households prefer to live near areas with more high paying jobs. Consumers dislike old housing stock and greater density within a building, while valuing density in the broader neighborhood.

We then simulate welfare and distributional consequences for 2026 (ten years after the reform) 
under alternative zoning scenarios. We focus on 10 year forecasts as this gives sufficient time for permits to be converted to actual housing units, and for prices to adjust. The baseline scenario takes zoning parameters from the pre-2016 period, while in the second scenario we impose the new 2016 zoning map on our supply equation which leads to a supply shock generating new housing supply in different areas throughout the city. We then apply a market clearing condition that households' aggregate choice probabilities must equal supply shares for each neighborhood, which delivers an equilibrium price vector. To estimate welfare effects, we calculate neighborhood characteristics for each equilibrium. First, we use equilibrium changes in population to update average commuting times, which may rise after upzoning due to the congestion costs. Next, we use equilibrium quantities to update building age, density, and other built environment characteristics. Finally, we evaluate households' utility functions at the new equilibrium to estimate the 2026 change in consumer surplus from the expected utility of access to neighborhoods with lower prices and new built environment characteristics 8

Counterfactual simulations show that the 2016 zoning reform leads to a $1.9 \%$ net increase in housing stock by 2026, resulting in a $0.5 \%$ average price reduction and modest welfare gains. However, there is variation across neighborhoods, with areas experiencing larger BAR shocks seeing more construction and greater price decreases, up to $17.1 \%$ and $4.6 \%$, respectively. Collegeeducated and higher-income households benefit the most from the reform, in part because they are the households most likely to take advantage of new housing. Welfare gains increase when accounting for changes in the built environment, and the economic value of zoning reform is strongly linked to newer housing and preferences for densification. Congestion costs only slightly reduce welfare gains via increased commuting times. In a separate simulation, we show that doubling allowed densities in upzoned neighborhoods produces larger welfare gains (1.63\% of city GDP over ten years).

However, we also find that nominal house price losses incurred by homeowners and landlords are about 16 times larger than consumer gains, which may explain the lack of homeowner support for more dense construction. While producer surplus accruing to developers is the largest among the other effects of the reform, even the aggregation of all potential gains does not match the nominal house price losses faced by existing real estate owners.

\footnotetext{
8 Our preferred model allows for the city population to grow as more housing is built, but we also test a model that assumes a closed economy. Details are shown in Section V.
} 


\section{Related Literature}

Zoning restrictions, such as limits on the density of buildings, are generally associated with increases in the cost of living (Glaeser and Gyourko, 2018; Brueckner and Sridhar, 2012; Ding, 2013), greater segregation and reduction in economic convergence (Trounstine, 2018; Ganong and Shoag, 2017), and result in the loss of economic output (Hsieh and Moretti, 2019). The literature studying the causal effects of zoning has primarily focused on cross-metropolitan area studies because of the variation in zoning rules across those geographies, with recent research focusing on block level differences around municipal boundaries (Turner, Haughwout and Van Der Klaauw (2014); Song (2021); Kulka, Sood and Chiumenti (2022); Kulka (2019)). Our main contribution here is to analyze how a zoning reform can be combined with micro-data to understand how zoning affects housing supply and long-run welfare.

Our paper also contributes to the literature on housing supply. One strand of this literature studies geographic constraints on housing supply (Saiz, 2010; Baum-Snow and Han, 2022). There is also a growing literature on structural models of housing supply. Murphy (2018) estimates a model of housing supply with a focus on the role of construction costs, while Paciorek (2013) studies the relationship between supply constraints and price volatility. Calder-Wang (2022) estimates the welfare of New York City residents given changes in availability of rental units due to the expansion of Airbnb.

Another important literature focuses on understanding the internal structure of cities - see (Fujita and Ogawa, 1982), (Fujita, 1989), Lucas and Rossi-Hansberg (2002), and Rossi-Hansberg and Redding (2017) for a recent review. Ahlfeldt et al. (2015) estimate a model of internal city structure to quantify the effect of densification. Harari (2020) investigates how city shapes in India affect transit accessibility, land use regulations, and city growth. A few recent papers study policy reforms within cities to estimate the value of urban policies and amenities. Allen, Arkolakis and Li (2016) studies optimal city structure, and apply their theoretical results to evaluate Chicago's existing zoning system. Tsivanidis (2022) estimates how new transit lines impact worker sorting and welfare in Bogota, and Balboni et al. (2020) estimates the impact of a new bus rapid transit system in Dar Es Salaam. We contribute to this literature by endogenizing housing regulations, and estimating how a zoning reform can improve availability of house units, increase affordability, and impact welfare.

This paper also fits in to three other broad topics. First, there is a large literature on the eco- 
nomics of urban density and agglomeration effects recently summarized by Duranton and Puga (2020). Those authors note that future progress in this literature could encompass the dynamics of building construction and raise empirical standards in the identification of causal effects, both accomplished in our work. Second, there is a growing literature studying how housing supply will respond in the face of larger demand for cities, recently summarized in Brueckner and Lall (2015); our paper provides a first complete evaluation of a zoning reform in a developing country city context. Finally, Epple, Gordon and Sieg (2010) and Combes, Duranton and Gobillon (2021) directly estimate production functions for housing. Our paper contributes to that body of work by estimating in detail how developers respond to zoning reforms at very granular geographies, credibly dealing with the endogeneity of zoning parameters.

\section{History of Zoning in São Paulo}

São Paulo has had three major zoning reforms in the past fifty years: 1972, 2004 and 2016. All of these reforms created "zone types" such as "Mixed Residential Use," with each zone type assigned a set of building parameters. Each of the city's blocks are assigned to a zone type, and the zone type designation determines the block's building parameters. The primary building parameter set in each reform is the built-to-area ratio (BAR), which is the ratio between the computable area of the building and the lot size, and fundamentally determines density of units developers can build given a land parcel $9^{9}$ Each block is also assigned to a building usage, such as residential, commercial or industrial purposes. Most zone types allow multiple building usages, but there are some that require only certain building types.

São Paulo's first city wide zoning regime was established in 1972 in response to rapid, haphazard, urban growth. Poor areas lacked enforcement of building rules allowing developers to build at their own will (Saconi and Entini, 2013). Wealthy neighborhoods, such as Jardim América who was administered by a British developer called Companhia City, had rigorous regulation implemented by private developers. The 1972 zoning law primarily aimed to preserve the architecture of richer neighborhoods, while guiding the city's growth towards the periphery (Giaquinto et al. 2010); this law also established that no new building could have a BAR above 4 . However, the majority of urban land resided in zones with a max BAR of one.

\footnotetext{
9 Other auxiliary building regulations, such as the shadow ratio - which is the ratio between the projected area of the building and the lot size - minimum and maximum lot sizes, setbacks, and heights have less variation over time and will be used as controls in our main supply model.
} 
São Paulo enacted a Master Plan in 2002 and a new Zoning Law in 2004, primarily in response to new federal laws mandating cities to have urban master plans. The 2004 Zoning Law had two features relevant for our analysis. First, the determination of specific building parameters, such as BAR, was decentralized to the "subprefeitura" or neighborhood level (São Paulo has 32 subprefeituras). In particular, the city would determine the zone type of each block, but the same zone type could have different building parameters based on the block's subprefeitura. Second, the city expanded the BAR parameter scheme to include minimum BAR, basic BAR and max BAR levels, each of which were chosen by the subprefeitura government for each zone-type within the subprefeitura. The law also required developers to pay extra fees to build above the newly established basic BAR levels ${ }^{10}$ The 2004 zoning reform also legislated, at the city level, that each district (a smaller unit than a subprefeitura with 96 total in the Sao Paulo municipality) - would have a limited stock of square meters above the basic BAR that could be constructed. Once a given district exhausted its available capacity above the basic BAR, no further construction could occur above the basic BAR level.

The 2016 zoning reform was initiated by Workers Party mayor Fernando Haddad in 2014 with the creation of a new city Master Plan. The stated goals of the reform were to provide dignified housing, guide urban growth, improve urban mobility, improve life in the neighborhoods, promote economic development, incorporate an environmental agenda, and preserve cultural heritage. A key feature of this reform was to standardize building parameters across the whole city by assigning a fixed set of building parameters to each zone type. Under the new reform blocks were assigned to a zone type, and then the city-wide building parameters associated with that zone type would be applied consistently across the city. This reform removed the power of local subprefeitura governments to set BAR and other building parameters within their jurisdictions. In addition to that, it simplified and centralized the BAR regulation, by implementing a Basic BAR of 1.0 in the entire city. The 2016 reform also eliminated the district-level maximum amounts that could be built above the basic BAR level.

A main idea in the 2016 law was to group zone types in to three major groups corresponding to a particular development strategy. Every zone type was labeled as one of the following categories: transformation, qualification, or preservation. The goal in transformation zones was to promote higher urban density, in terms of both residential and non-residential structures, near

${ }_{10}$ A building developed with a BAR between the basic and max BAR was required to pay the so called "onerous grant" fee, charged per square meter built above the basic BAR level. Buildings developed between the minimum and basic BAR did not have to pay any extra fees. 
the city's main transportation corridors. The aim was to reduce the city's traffic and bring people closer to their jobs by improving land use in areas closer to medium and high public transportation networks, such as train, subway, monorail, and bus corridors. The objective in qualification zones was to improve life in residential neighborhoods by favoring moderate urban density; the standard max BAR for these zones was set at 2.0. Zones were designated "preservation" status with the purpose of preserving the environment and cultural heritage of the city. Figure A1 shows a color map of the 2016 reform, with the transformation zones in maroon, qualification zones in gray and yellow, and preservation zones in green. Figure A2 displays the striking detail of the block-by-block land use regulation in the middle class neighborhood of Jabaquara.

The 2014 Master Plan and associated 2016 zoning reform are valid for 16 years. Given that much of the predicted worldwide urban growth will occur in developing countries, it is interesting to test whether a zoning reform of this type, in a developing country city, actually leads to changes in the built environment and improvements in resident welfare 11

\section{Data}

\subsection{Zoning data}

Zoning data comes from the Cidade de São Paulo Desenvolvimento Urbano. We geo-reference and digitize maps of zoning boundaries at the block level for 2004 and 2016; there are 22 zone types in 2004, and 38 in 2016. In total, we are able to match 45,082 of São Paulo's city blocks to a zone-type, or $96 \%$ of the city's 46,987 blocks. We then match these zone-types to the relevant minimum and maximum allowable density parameters at the neighborhood and zone level. From this, we calculate the maximum allowable BAR. In some cases, these parameters vary within a zone-type depending on the size of the lot. In these cases, we define the maximum allowable density parameter as the maximum of all possible values 12

We obtain the max BAR values in both periods for 43,250 city blocks. ${ }^{13}$ The underlying BAR

\footnotetext{
11 The reform may be toothless if, for example, developers can evade zoning rules via paying bribes - in such an environment zoning rule changes would have little impact as even existing rules are not enforced. Also, it is possible that zoning rule changes translate in to only minor built environment changes because of other market frictions, such as problems in land acquisition (Bryan et al. 2017) or developer credit constraints.

12 In defining the max BAR before 2016, we account for the fact that some blocks are in districts where the allowed capacity for building above the basic BAR level has been exhausted. In these blocks, the "effective" BAR prior to the 2016 reform is the basic BAR level.

13 Note that this is less than the 45,082 city blocks for which zoning information is available. These missing blocks are primarily parks, municipal areas, and bodies of water. The remainder are cases in which zoning information was available, but BAR parameters were missing or not relevant for the particular category.
} 
variation for each block is mapped in Figure 1, along with the borders of the city's subprefeituras. More than $50 \%$ of all blocks experienced an increase in max BAR. There is a somewhat general pattern of blocks in the outskirts of the city experiencing positive changes in maximum allowable $\mathrm{BAR}$, and blocks within the central regimes experiencing negative changes or no change in maximum allowable BAR. However, there are many blocks in the central area that received positive (green) changes in their maximum allowable BAR - typically along major transportation corridors. Figure A3 presents binned scatter plots on the relationship between block level characteristics (xaxis) and the change in maximum allowed BAR from the 2004 to 2016 zoning regime. On average, blocks with lower levels of BAR in the 2004 regime received greater increases in allowable BAR. We also see that blocks with higher residential shares of constructed area received greater BAR increases. Blocks with greater density (as measured by the log constructed area per square kilometer) received on average lower changes in BAR, and blocks with greater average land values also received lower changes in BAR.

\subsection{Permitting data}

Data on building permits were scraped from the Urbanism and Licensing Center of the City of São Paulo, or SMUL. Building Permit data is useful in tracking where and at what volume development is taking place in the city of São Paulo. There are over 50 different types of permits issued through SMUL, such as permits for demolition, installation of security systems, etc. but the majority of them are related to the construction of new buildings. The data is organized by quarter and by year of its filing and includes information about which region of the city the permit is in, the address, the zoning and land use classification, as well as the engineers, architects, and owners leading the project.

We obtain data on approximately 30 thousand total residential permits for the period 19972020 , of which approximately $85 \%$ are multifamily buildings and $15 \%$ are single family dwellings. We then aggregate the number of permits and the number of units at the quarter-block level, yielding a panel of 3,195,116 quarter-block observations. The main outcome variables are the quarterly count of total new building permits for single and multifamily buildings, plotted in

Figure A4. Permitting activity was much larger in the mid-2000s, and declined since 2014 due to the national economic and political crisis. Interestingly, multifamily permits filings more than doubled since the approval of the 2016 reform.

Our data also includes commercial building permits, such as offices, hotels, retail, and educa- 
tion facilities. Figure A5 plots the number of commercial building permits over time and reveals a very small and declining number of permits after the 2016 reform. Since the main economic impact of the reform was on residential permits, in the rest of the paper we mostly focus on those outcomes and relegate some commercial permit estimates to the appendix.

\subsection{IPTU data}

Information on the stock of buildings in São Paulo, including constructed area, lot sizes, assessed construction value, number of units per building, and assessed land value comes from the IPTU property tax data, which we obtain annually from 1995 to 2019. In 2016, the year of the zoning reform, this data covers 3,316,608 individual tax paying units in 1,582,532 unique buildings. The construction and land values are assessed values produced by the São Paulo property tax assessor office, and form the basis for annual property tax payments; these values are only indirectly based on market transactions. We collapse this data to the block-level to obtain block-level average lot area and constructed area in $m^{2}$, as well as mean land value and construction value per $m^{2}$. We also obtain the share of lot and constructed area with residential vs. commercial designation by the property tax authority, as well as the total number of units and buildings in each block. This information is available in the pre-2016 period for a total of 43,990 São Paulo city blocks, or $94 \%$.

\subsection{Listings and Price Data}

Given that the IPTU value data is based on assessments as opposed to market values, we also collect listing price data from two different sources. The first source is the online marketplace Properati. The data has unique entries for approximately 200,000 buildings listed for sale and for rent in 2016. Each listing in the system contains the price, the type of transaction (rent or sale), the location, the type of unit (i.e. apartment, house, office, etc.), and a general description of usage (residential, commercial, bare-land or non-specified). The IPH (Hiperdados-Properati Index), which used data from Properati, was the most complete real estate pricing indicator in Brazil until it was sold and renamed to Casafy (who stopped publishing the data in 2016).

DataZap, a real estate analytics company that also has public online interfaces similar to Zillow, provided prices and listing for more recent periods. From DataZap we obtained data containing aggregated block level information on the number of listings, average price of listings per block, 
and average characteristics of listings (such as number of rooms, square meters) for the years 2019-2022 14 The data separately covers apartments and single family homes, and within these categories data is provided for sales and rental listings.

\subsection{RAIS Data}

We measure labor market economic activity at the block level using the total formal sector wages paid to workers whose firm address is within a block. We obtain this variable from the RAIS data, which is individual level monthly wages data for all formal sector workers in São Paulo. We aggregate the individual monthly wage data up by year, and then further aggregate at the block level to obtain total annual wages paid per block. This data is available from 2000-2019.

\subsection{Commuting Zone Survey Data}

We use commuting survey data from the "Pesquisa Origem e Destino 2017" survey. The commuting survey covered São Paulo metropolitan statistical area households and includes information on demographics, place of residence and place of work. We take as our sample the 24,800 households for which the household head is working. The survey was stratified by commuting zones, and for this employed sub-sample we obtain 492 commuting zones within the São Paulo metropolitan area (i.e. including both the São Paulo municipality that we study as well as the surrounding suburbs). 329 of these zones are within the municipality itself. From this data, we take individual home and work locations, which we use to calculate commuting distances, household head education and age, household size and total monthly income, and dwelling ownership status. We also use this data to estimate several commuting zone-level characteristics, including average income, education, and the share of paved roads.

\section{Border Discontinuity Design and Results}

\subsection{Empirical strategy}

Our primary identification strategy to estimate the impact of zoning reform is to compare the evolution of permitting activity in geographically close blocks with different treatment status.

\footnotetext{
14 DataZap cannot share its microdata because of confidentiality issues. Since DataZap counts listings on a monthly basis, from three different sites, we correct for this overestimate by dividing the total number of listings in each block by 15, which is the average number of months listed (6) times the average number of sites listed (2.5)
} 
To construct regression discontinuity plots we begin by defining as "treated" all blocks in zones that experienced an increase in maximum allowable BAR as a result of the 2016 reform. Control blocks are those that fall in zones which experienced either no change or a reduction in max BAR. Then, for each treatment block, we calculate the distance in kilometers to the nearest control block. Distance is calculated from the block's centroid to the edge of the nearest block in the other group. This distance defines the running variable in our border discontinuity design for treatment blocks. The running variable for control blocks is the (negative) distance to the nearest treatment block. Our boundary discontinuity design focuses on outcome comparisons between control blocks with small absolute values of the running variable (i.e. control blocks near to treatment blocks) and treatment blocks with small values of the running variable (i.e. treatment blocks near control blocks) ${ }^{15}$ In the Appendix we report the number of blocks in 50 meter bins of the running variable, and find no discrete jump around the cut-off (Figure A6).

Our key identification assumption is that, in the absence of the 2016 zoning reform, outcomes would have evolved similarly across the zoning borders at which the change in max BAR switches from positive to non-positive. To corroborate this assumption Figures A7 and A8 assess the covariate balance of existing structures and economic activity across treatment and control blocks in the year prior to the zoning reform. The x-axis groups blocks within .1 kilometer bins away from the cut-off, and the $y$-axis plots the binned-average change in covariates. Regarding the built environment, we find no meaningful differences in block density (constructed area per square meter), average land or constructed value, number of buildings, or residential/commercial share of constructed area at cut-off. We also find no meaningful differences in total employees in private firms, mean per-worker wages, total wages paid, and the number of private firms 16

The core treatment variation is the change in maximum allowable BAR in nearby treatment and control blocks. Figure 2 shows how the change in BAR from the 2004 to 2016 zoning regime varies as we move towards the 2016 zoning borders from control blocks to treatment blocks. The

\footnotetext{
15 We investigated a "bunching" strategy where we estimated how the fraction of new buildings built at exactly the maximum allowable BAR changes with the reform; in principle such a strategy could be used to estimate the marginal increase in constructed area resulting from an increase max BAR. The primary challenge is that neither the permit nor IPTU data report the 'computable' built area measure required to exactly calculate a building's BAR. Instead these data just report constructed area. Given the bunching strategy relies on exact measures of BAR, we chose not pursue this approach. We do have a strong sense that max BAR limits were binding throughout the city, from the fact that almost all of the allowed building up to max BAR levels was utilized prior to the reform.

16 Appendix Table A7 presents regression discontinuity estimates of these differences. Out of twelve comparisons we find one variable (log of aggregate private employee wages) is statistically significant at the $10 \%$ level or higher. Based on Figure A8 this statistical difference does not correspond to a jump at the cut-off that is economically meaningful relative to the bin by bin variation.
} 
figure shows averages of max BAR by bins of $.1 \mathrm{~km}$ distance to the closest border, i.e., the closest block from opposite treatment status. City blocks just to the left of the cut-off experienced an approximate .1 decrease in their maximum allowable BAR, while blocks just to the right of the cut-off experienced an approximate 1.3 increase in their maximum allowable BAR. In appendix Figure A9 we show that the first stage is almost identical when restricting the control group to blocks with no change in max BAR. ${ }^{17}$

To estimate the treatment effect of higher BAR levels, we use the following regression discontinuity model:

$$
y_{i j}=\beta 1\left\{x_{i j}>0\right\}+f\left(x_{i j}\right)+\delta_{j}+\epsilon_{i j}
$$

where $y_{i j}$ is an outcome in block $i$ which is located in subprefeitura $j, x_{i j}$ is the value of the running variable for block $i$ in subprefeitura $j, \delta_{j}$ is a subprefeitura fixed effect, and $\epsilon_{i j}$ is an error term. The indicator function $1\left\{x_{i j}>0\right\}$, designating treated blocks, is our main independent variable of interest, and $\beta$ is our estimate of the treatment effect. The function $f(\cdot)$ is a polynomial of distances fully interacted with $1\left\{x_{i j}>0\right\}$. We cluster standard errors at the commuting zone level; there are 329 commuting zones in our data so this clustering is substantially more conservative than clustering at the block level. Commuting zones are also a natural level to cluster given this will be our neighborhood unit of analysis in the supply/demand model that estimates welfare effects.

Table 1 reports RD point estimates and standard errors for our "first stage" using four versions of this specification with change in max BAR as the outcome variable. Column 1 compares all treatment versus control blocks (i.e. only includes the indicator $1\left\{x_{i j}>0\right\}$ in the model), column 2 adds a linear control of the running variable (and interacts it with a treatment indicator), columns 3 adds quadratic controls, and column 4 adds cubic controls. RD estimates show a stable 1.4 point estimate. In Panel B of table 1 we add subprefeitura fixed effects, so that all variation comes from changes within subprefeitura. Estimates remain practically unchanged, suggesting that the reform treatment is not driven solely by pre-reform differences in how different neighborhoods controlled zoning parameters.

\footnotetext{
${ }^{17}$ Figure A10 reports the average max BAR values in our treatment and control blocks before and after the 2016 reform, not just the change in max BAR shown in Figure 2 Treatment blocks had lower max BAR values prior to the reform relative to control blocks, and have higher max BAR values after the reform. The pre-existing differences prior to the reform are to some extent mechanical, in that treatment blocks are defined as those which experienced an increase in BAR in the 2016 reform. But the fact that max BAR did differ prior to the reform, even in a narrow bandwidth around the border, strongly suggests that we should focus on how outcomes change before and after the reform, as opposed to just analyzing a cross-sectional border discontinuity design after the reform.
} 


\subsection{Reform Short-Run Effect on Building Permits}

We now use the same set of treatment and control blocks to estimate the causal effect of the greater allowable BAR on building permits. Figure 3 splits our permit outcome variable into multifamily permits (top two figures) and single family permits (bottom two) figures. The outcomes represent average quarterly building permits in a block, and the left panels show pre-reform data (2012q2 - 2016q1). Focusing on multi-family permits first, the pre-reform panel shows a small difference in permits at the discontinuity. In contrast, the post-reform period show that treatment blocks just on the higher BAR side of the zoning border experienced approximately 0.004 more permits issued relative to the control side of the border (0.0085 versus 0.0045$)$. The higher BAR allowance causes almost a doubling of average multi-family permits filed per quarter relative to control blocks.

Interestingly, the zoning treatment effect on permits is concentrated in multi-family units. The bottom two panels of figure 3 show that not only are total number of single-family permits smaller in both pre- and post-reform periods, but also that there are no differences around the spatial discontinuity. Overall, the causal effects of the reform are concentrated in multifamily permits, consistent with these buildings being more sensitive to BAR constraints. 18

Figure 4 presents separate regression discontinuity estimates for each half-year, including both pre- and post-reform quarters. The RD estimate is generally not statistically significant prior to the reform. We see the treatment blocks experiencing greater permitting activity approximately two half-years after the reform, and the point estimates more than double three years after the reform. The emergence of the treatment control differences approximately one year after the reform is consistent with a causal effect of the reform, as opposed to pre-existing differences correlated with zoning changes 19

Table 2 reports RD estimates for multi-family permits, in analogous form to the presentation

\footnotetext{
18 Both pre- and post-reform figures show a downward slope in average quarterly permitting activity as we move from deeper in the control area towards the cut-off, and then a slightly positive slope from the cut-off towards deeper in to the treatment area. We find a similar pattern in the total number of buildings per block in the 2015 IPTU data (see Figure A7).

19 Appendix Figure A11 presents similar estimates for commercial building permits. Point estimates are generally close to zero, and do not present a different pattern before and after the zoning reform. As shown in Figure A5 the level of commercial permits just prior to the reform is substantially lower than residential permits; general interest in commercial building may have been too low at this time to create a statistically detectable change in commercial development. Also, Appendix Figure A12 presents similar figures for two models: Figure A compares zero BAR change blocks against positive BAR change blocks, while Figure B compares zero BAR change blocks against negative change blocks. Figure A shows similar results to 4 , as expected, while Figure B shows post-reform quarterly estimates that are mostly around zero and not different from pre-reform estimates. These results indicate no practical outcome differences between the groups of blocks with zero and negative BAR changes.
} 
in Table 1. Panel A reports RD estimates ranging from 0.0044 to 0.0048 (excluding the Column (1) estimate which does not control for the running variable). The inclusion of subprefeitura fixed effects in Panel B has the impact of reducing the magnitude of causal estimates to a range of 0.0023 to 0.0031 . This means that part of the permitting effects are explained by differences in subprefeitura boundaries ${ }^{20}$ Combining the reduced form estimates with the first stage max BAR treatment magnitudes estimated in table 1 reveals that increasing max BAR by 1 leads to an increase in multi-family permits between $28 \%$ - 63\%, relative to nearby control blocks. 21

Figure A13 presents regression discontinuity estimates on the treatment effect of allowing greater BAR ratios separately for blocks with below and above median land values. The binned averages in these plots are produced by first splitting the sample in to below and above median groups, and then using the distance to the nearest zoning border as the running variable ${ }^{22}$ Nonetheless, the figure suggests that the zoning treatment effects are largest in areas with higher pre-existing land values. The zoning reform appears to have spurred greater construction activity where developers expect greater demand and higher profits.

Figure 5 tests if the multi-family permits point estimates, pre and post reform, change according to how much of the sample we use away from the cut-off (i.e. considering larger bandwidths). The x-axis shows bandwidths in kilometers around the cut-off (i.e. a bandwidth of .1 includes control and treatment blocks within 100 meters of the cut-off). The y-axis shows the regression discontinuity estimate. The top panels show post reform effects with and without subprefeitura fixed effects. Estimates without subprefeitura fixed effects become larger as the bandwidth gets bigger. Post-reform estimates with fixed effects are more consistently around .002 and .003, independent of the bandwidth size. The bottom panels show similar specifications for the pre-reform period of 2012Q2 to 2016Q1. While estimates without fixed effects show statistically significant effects for bandwidths above .15, those estimates become smaller in magnitude and not statistically different from zero upon inclusion of subprefeitura fixed effects.

Our short-run analysis has focused on changes in BAR in nearby blocks; given that the reform

\footnotetext{
20 Appendix Table A1 applies the same RD strategy in a Poisson estimation, finding similar results. The Poisson functional form will be used in the final supply model described in the next section as it can better account for the discrete count nature of housing units.

21. For brevity we do not include a fuzzy regression-discontinuity model coefficients and standard errors, because our counterfactual results ultimately depend on our full supply model estimated later - where we present standard errors on the instrumented BAR variable. The coefficients in the fuzzy regression discontinuity model would be the ratio of our reduced-form coefficients in Table 2 and first-stage coefficients in Table 1

22] Note that this procedure does not necessarily include treatment and control units on each side of every border (as it is possible that treatment units on one side of a border could have above median land values but the corresponding control units had below median values).
} 
included both changes in BAR and zone type designations by block, it is useful to characterize how nearby treatment and control blocks differ in zone type designations as well. Appendix Figure A14 and Appendix Table A2 show that there are no differences in the share of blocks that are designated for residential use - this could potentially confound our results if more treatment blocks had changed from industrial to residential use, for example. But as the law intended, we do find small increases in the share of treatment blocks designated as transformation zones, while control blocks have small increases in the share of blocks designated as qualification and preservation.

Next, we look at other zoning parameters that could be changing alongside max BAR. Appendix Figure A15 and Appendix Table A3 show RD results for building height, basic BAR, shadow ratio, and maximum lot size. Again, as expected, we find small discontinuities in all variables. More interestingly, we re-estimate our main RD specification for both new multifamily units and max BAR change, now including those additional zoning parameters as additional controls. Appendix Table A4 shows that all treatment coefficients drop by about $1 / 3$. However, when dividing the new reduced form effects by the new smaller first stage, we find results similar to the baseline estimates shown in Tables 1 and 2. In the complete supply model described in the next section we will estimate development activity as a function of all local zoning regulations, not just max BAR.

\subsection{Spillover Effects?}

We identify the short-run treatment effect of relaxing zoning rules by comparing areas that received a higher max BAR designation to nearby areas that did not receive such treatment. In this section we analyze the extent to which increases in allowable BAR levels might affect nearby blocks (i.e. spillover effects). On the one hand, developers may act independently, and spillover effects might be small during the post reform period when developers are simply filing for permits. But there are at least three reasons to estimate spillover effects in our context. First, projects could move from nearby control blocks to treatment blocks, leading us to over-estimate the effect of the BAR reform. Second, buildings in nearby control blocks could increase if the greater expected density in the nearby treatment blocks make nearby control blocks more attractive areas to develop as well. Finally, part of the treatment effect in treatment blocks could reflect agglomeration benefits of other nearby treatment blocks - although these benefits would likely appear with long lags. 
We follow a simplified variant of the methodology in Diamond and McQuade (2019) to assess the importance of spillovers in the context of a highly localized zoning reform. The basic strategy is to treat both treatment and control blocks near a zoning boundary as "treated," in the sense that they are nearby to an area where a major zoning change occurred. We compare outcomes for these blocks near boundaries to a "pure control" set of blocks that are farther (i.e., greater than half kilometer) away from the boundary, before and after the reform. To operationalise this spatial difference-in-differences strategy we estimate the following regression model:

$$
y_{i t}=\sum_{j=1}^{5} I(t>2016 Q 2) * I\left(d c_{j *-.1}=1\right)+\sum_{j=1}^{6} I(t>2016 Q 2) * I\left(d t_{j * .1}=1\right)+b_{i}+q_{t}+\epsilon_{i j}
$$

where $y_{i t}$ is the number of permits issued in block $i$ in a quarter $t, I(t>2016 Q 2)$ is an indicator for post reform, $I\left(d t_{j .1}=1\right)$ is an indicator for a treatment block that is $j * .1 \mathrm{~km}$ away from the nearest control block, and $I\left(d c_{j *-.1}=1\right)$ is an indicator for a control block that is $j * .1 \mathrm{~km}$ away from the nearest treatment block. The equation also includes block and quarter fixed effects. The omitted category consists of control blocks more than $.5 \mathrm{~km}$ away from the boundary, and all treatment blocks with distance greater than $.5 \mathrm{~km}$ are bunched in a $0.6 \mathrm{bin}$.

Figure 6 presents the estimated coefficients. On average permits are higher in all treatment blocks relative to all control blocks. The difference between treatment and control groups is slightly larger within $.1 \mathrm{~km}$ to the boundary. But they are not statistically different from each other, in part because the distance bins are quite small. Moreover, we do not observe control blocks near treatment blocks appearing to have particularly low permit averages. Relative to the omitted category, the distance of a given treatment (control) block away from the boundary does not appear to be strongly associated with permitting activity. The finding of non-existent spillover effects in building activity is consistent with Turner, Haughwout and Van Der Klaauw (2014) finding of small effects of land-use regulations on nearby property prices.

\subsection{Reform Medium-Run Effects on Permit Approvals, Construction, Listings, and Prices}

So far we have analyzed the reaction of developers to zoning reform based on the fastest outcome we can observe, i.e., the filing of zoning permits. Now, we look at medium-run effects of the reform on different outcomes. First, we look at differences in the number of building permits that 
were actually approved by the city. It turns out that more than 75 percent of permits are approved within 3 to 4 years of their filings, a number that only slightly increased after the 2016 reform. In Table A5 we estimate a similar RD for total multi-family permits that were approved after the reform, and find estimates in the range of 47-88 percent increase in approved permits for each 1 unit of max BAR increase. Those ranges match our estimates for filed permits.

Given the lags involved in filling and approval of permits, and the additional years necessary to observe any type of multifamily projects - which generally have extra construction delays using constructed buildings as an outcome would give a biased picture of the zoning reform's full effects, at least in the medium run. However, we can use data prior to the reform to estimate the conversion rate of permits to constructed buildings, in order to help quantify how our results on permits are likely to convert to constructed buildings. Figure A16 estimates a block-level eventstudy model on the impact of a permit being issued on the density of new construction, measured as new constructed area divided by total land area in the IPTU data, in the period prior to the reform (2004-2016). The figure suggests that a new permit issued in a block is correlated with increases in density up to 15 years after the issuance. Of course, these calculations are only useful to the extent that past relationships between permits and finished construction hold. We will use this relationship to translate the completely observed short-run permit effects into construction effects when we estimate our structural model to evaluate welfare.

Next, we use DataZap information to test if the availability of housing units for sale actually increased by 2022, six years after the reform. We calculate the total number of listings of units for sale (both houses and apartments) at the block level during that year, and compare with a similar total for the years 2019. Given the large lags involved in applying for a permit, getting an approval, and then constructing a property, the year 2019 is actually a good baseline to observe a potential effect of the reform on housing availability. Figure 7 shows the boundary discontinuity estimates for the change in listings of properties for sale, while Table A6 provides points estimates under different specifications. In our preferred model we find that blocks with higher max BAR had 2.1 extra listings in 2022, which is a 10.3 percent increase relative to the average number of listings in 2019.

We do not apply a similar border discontinuity design for listing prices. Housing markets are generally not segmented by blocks, and therefore availability of homes for sale in block may impact prices in a broader neighborhood area - prices in fact may evolve smoothly around zoning boundary discontinuities. Instead, we aggregate our listings by commuting zones and compare 
number of listings and listing prices by that geography.

Figure 7, left panel, shows that commuting zones with larger average increases in max BAR also had larger growth in availability of homes for sale. The regression line shows that a 1 point increase in max BAR is correlated with a 10.9 percent increase in listings growth, which is remarkably similar to the casual estimates for that variable using the boundary design. The right panel shows a similar comparison for listing prices. Now, the slope is negative, with a 1 point increase in max BAR being correlated with a 5.7 percentage point reduction in home prices ${ }^{23}$

In summary, these short and medium-run outcomes suggest that the reform had strong effects on blocks and neighborhoods that were allowed to have more densification. Developers immediately applied for more new permits in those blocks, and also received more new approvals a few years later. Subsequently, those constructed units were listed for sale in blocks with higher max BAR, increasing housing supply. When aggregating listings at the neighborhood level, the increased supply was accompanied by reductions in prices. Those reduced form results suggest important changes in welfare for city dwellers. But since other aspects of neighborhoods may be changing, such as congestion and commuting costs, it is important to include all these factors in a model to fully understand the magnitude of the welfare effects and its distributional consequences.

\section{Welfare Evaluation}

In this section we estimate an equilibrium model of supply and demand to predict the long-run welfare consequences of the Sao Paulo 2016 reform. Our supply model is an extension of the reduced form results presented above, and allows for endogenous zoning regulation and prices. On the demand side we follow the standard neighborhood choice approach, where individuals maximize utility when choosing neighborhoods as a function of observed and unobserved location features. The richness of the Sao Paulo data allows us to estimate the value of both positive and negative aspects of more densification in each neighborhood. We then back out equilibrium prices under the assumption that quantity supplied equals to quantity demanded at the neighborhood level, and simulate welfare and distributional consequences under alternative zoning scenarios.

233 The price figure shows residualized price variation which is created as follows. We regress average multifamily prices per square meter from DataZap at the block level on average characteristics of apartments listed in the block (number of bedrooms, useful area, and construction year) we take the residuals from this regression as our measure of listing prices. 


\subsection{Model of Residential Supply}

We model the construction of new residential housing as an exponential function of housing prices, building density restrictions, and other location characteristics. The Poisson functional form is used because of the strictly positive, discrete count nature of housing units ${ }^{24}$ In particular, we estimate the following supply equation for location $j$ :

$$
E\left[s_{j} \mid p_{j}, M_{j}, X_{j}^{s}\right]=\exp \left(\alpha^{s} p_{j}+\psi M_{j}+\beta^{s} X_{j}^{s}\right)
$$

where $s_{j}$ is the total number of building permits in location $j, p_{j}$ is the average residential 2016 listing price in $j, M_{j}$ is the maximum allowable BAR in neighborhood $j$, and $X_{j}^{s}$ is a vector of other housing and regulatory characteristics of location $j$ that affect development activity. These other variables include construction density in $j$, the average building age, the average number of units per building, and the average value of the pre-2016 BAR zoning parameters, and the 2016 nonBAR zoning parameters (maximum shadow ratio, minimum and basic BAR, maximum height, minimum and maximum front setback, and maximum area), averaged across all blocks in $j$.

We estimate the supply model at the subprefeitura-quantile-level, where city blocks are aggregated into 40 quantiles of our regression discontinuity running variable (i.e. distance to the 2016 zoning change boundary) within each subprefeitura. This aggregation is done for two reasons: First, price information is relatively sparse at the block level, and so aggregating allows us to get price information for all the observations. Second, the distance quantiles allow us to still exploit the boundary approach to identify the Max BAR effect. The estimation procedure will focus on comparisons between permit outcomes for the quantiles just above and below the BAR increase cut-off within subprefeituras. Summary statistics for our supply variables are shown in Table A10.

\subsubsection{Instrumental variables}

In equation 3 we treat $p_{j}$ and $M_{j}$ as endogenous neighborhood characteristics, while assuming other physical location characteristics are exogenous. The assumption is that developers take these other characteristics as given when making development decisions, and do not adjust their estimate of these characteristics when making supply decisions over the 10 year horizon. This assumption is reasonable because changes induced by new construction to these variables are rel-

\footnotetext{
24 We consider the robustness of the estimates to a simple log-linear specification - which drops locations with zero permits - and find qualitatively similar results. We prefer the Poisson method to a simple log-transformation of the outcome, as it preserves all observations in the data.
} 
atively small, given these variables are generally characteristics of the total stock of buildings. We caveat that the plausibility of this assumption depends on the size of the reform we are evaluating; while credible for the 2016 change in policy, other larger reforms could affect stock variables more significantly. To address endogeneity in the price $p_{j}$ and max BAR $M_{j}$, we estimate the supply model with multiple instruments using the GMM estimator of Mullahy (1997) with additive errors to form moment conditions. The instrument set is $W_{j}^{s}=\left[T_{j}, B_{j}, X_{j}^{s}\right]$. The first excluded instrument $T_{j}$ - used for max BAR - is an indicator for whether the subprefeitura-quantile $j$ is treated by the 2016 reform. To leverage the regression discontinuity design for identification of $\psi$, we also include distance to the boundary $D_{j}$, and $D_{j} \times T_{j}$ as control variables in $X_{j}^{s}$. Validity of the max BAR instruments was discussed in detail in the previous sections.

The second excluded instrument, $B_{j}$, instruments for market price. A major challenge in the housing supply literature is the identification of supply elasticities with respect to price. Inspired by Baum-Snow and Han (2022), we instrument for price using a Bartik-style demand shock. The idea is to exploit plausibly exogenous variation in exposure to national labor demand growth for neighborhoods based on the historical presence of sectors that experienced substantial national growth. Formally, let $B_{l}$ be our Bartik instrument defined as:

$$
B_{l}=\sum_{k} z_{l k} g_{k}^{- \text {SaoPaulo }}
$$

where $k$ indexes one of the 59 economic sectors from the RAIS data, and $l$ indexes commuting zone. $g_{k}^{- \text {SaoPaulo }}$ is the national growth rate in employment, excluding the Sao Paulo municipality, in sector $k$ from 2007 to 2017. $z_{l k}$ is the commuting zone level sector $k$ share of employment in 2007 (the "initial share"); $z_{l k}$ is calculated as $\frac{L_{l k}}{\sum_{k} L_{l k^{\prime}}}$, where $L_{l k}$ is the total number of formal sector employees in the RAIS data in commuting zone $l$ in sector $k$, divided by the sum of employees in that commuting zone excluding the sector. ${ }^{25}$ Lastly, we aggregate the commuting-zone-level Bartik shock, $B_{l}$, into a subprefeitura-by-quantile shock using the weights in Appendix A.

Our identification assumption is that our Bartik instrument only affects new permit issuances in 2017 through its effect on prices in 2017. The threat to identification is that the initial shares in 2007 could be related to 2017 permit issuance levels through some non-price mechanism conditional on our control variables. While we cannot directly test this assumption, we note that our

25] Appendix figure A19 shows how these initial shares are distributed across our 329 commuting zones. Retail tends to have the largest share of employment in 2007. Appendix Figure A18 shows national employment growth rates from 2007 through 2017 for the 59 economic sectors. 
specification controls for a very large set of building restrictions and neighborhood characteristics, which hopefully reduces the chance that employment shares have a non-price relationship with building activity.

Appendix Figure A20 shows a scatter plot of the first stage relationship between market prices in 2017 and our Bartik instrument. Each point is a commuting zone. There is a positive correlation; commuting zones that had higher initial shares in sectors that ended up growing faster nationally also do have higher price levels in 2017. The right panel of the figure shows a binned scatter plot version, indicating a strong first stage 26

\subsubsection{Supply estimation results}

We estimate the supply model using data on 5,375 new residential building permits filed with the São Paulo city government between 2016-2019. The right-hand-side variables are taken from either IPTU or the block-level zoning maps; all of these variables are averaged across blocks within the subprefeitura-quantile. In total, we obtain 1182 subprefeitura by quantile observations, of which 900 have any new residential construction permitting activity over this period.

Table 3 presents the estimated supply coefficients. Column (1) does not instrument for either endogenous variable, while column (2) estimates the model using only the regression discontinuity instrument for $M_{j}$. Column (3), our preferred specification, instruments for both $M_{j}$ and $p_{j}$ with the RD and Bartik IVs, respectively. The estimates in (3) imply that a one-unit increase in maximum allowable BAR at the mean leads to approximately 5.05 additional new building permits for the average unit ${ }^{27}$ This estimate is in line with the RD estimates from Table 2 . The price coefficient in column (3) implies that a 1,000 reais increase in price (18.7\% of the mean) is associated with 2.34 new permits on average ${ }^{28}$ Note that column (1) substantially underestimates both coefficients by ignoring endogeneity. Instrumenting for BAR with the RD nearly doubles the estimated coefficient. In addition, the price elasticity estimate rises from 0.149 to 0.415 from columns (2) to (3). This suggests a downward simultaneous equations bias in estimating the supply elasticity.

In columns (4)-(5), we show that BAR effects are small and statistically insignificant for sin-

\footnotetext{
26 Appendix Figure A21 shows the corresponding figures for number of new permits issued in the post-reform period against the Bartik IV (the "reduced form" relationship). Goldsmith-Pinkham, Sorkin and Swift (2020) recommend analyzing how the overall instrumented coefficient compares to the coefficients estimated based on each possible sector as an instrument. Figure A22 shows this plot for our Poisson model. We see that most sectors are close to the overall estimate, suggesting that the price elasticity coefficient is not determined by one particular outlying division.

$275.05=4.55 *(\exp (0.747)-1)$, where 4.55 is the average of the outcome variable.

$282.34=4.55 *(\exp (0.415)-1)$.
} 
gle family permits, but large and significant for multifamily permits. This is consistent with the reduced form results in Section 5. Both housing types, however, exhibit similar degrees of price responsiveness ${ }^{29}$

\subsection{Model of Residential Demand}

\subsubsection{Choice model}

Our model of residential housing demand follows a standard discrete choice framework (Berry, Levinsohn and Pakes, 1995: Bayer, Ferreira and McMillan, 2007). Household $i$ chooses between $j=1, \ldots, J$ alternatives, where the alternatives are one of 329 commuting zones within the city of São Paulo. The outside option is living outside the city - in the suburbs - taken by roughly $40 \%$ of the individuals in our residential commuting data. Individual utility from choosing to live in zone $j$ will be:

$$
u_{i j}=\alpha_{i}^{d} p_{j}+\beta_{i}^{d} X_{j}^{d}+\gamma_{i} \tau_{i j}+\xi_{j}+\epsilon_{i j}
$$

where $p_{j}$ is the price of housing in zone $j$, measured as the average Properati listing price per square meter in commuting zone $j . X_{j}^{d}$ is a $K$-dimensional vector of housing amenities of location $j$. This includes an index of residential commuter market access (RCMA) that measures the extent to which $j$ is located near high-paying jobs, using travel times from a zone commuting matrix ${ }^{30} X_{j}^{d}$ also includes the average age, in years, of the stock of housing units, average number of units per building, the overall zone-level constructed area density - defined as the sum of all constructed area divided by the zone geographic area - the share of households with a paved road, the average zone income, and the share of zone adults with a college degree. The term $\tau_{i j}$ measures commuting costs as the predicted travel time in minutes between the zone in which $i$ works, taken as given,

\footnotetext{
29 In the Appendix, we consider several robustness tests for the supply model. Our additive error structure, following a standard nonlinear regression setup, implies as an identifying assumption that the instruments $W_{j}^{s}$ are exogenous to the exponential function of the endogenous variables. Table A11 allows the error term to enter multiplicatively instead of additively in forming the GMM moment conditions. The results are similar. Table A12 considers approvals, rather than all permit filings, and finds nearly identical magnitudes. If anything, using filings is a conservative approach. Finally, Table A13 estimates the model with a linear 2SLS specification, allowing us to assess instrument strength with the first-stage Kleibergen-Paap F-statistic. The sign and significance of the coefficients is unchanged, and the instruments are highly correlated with endogenous variables, allaying concerns about weak instruments.

30 We define the RCMA for zone $j$ as:

$$
R C M A_{j}=\sum_{i \in I_{j}} \frac{w_{i}}{d_{i j}}
$$

where $I_{j}$ is the set of zones that have at least one worker living in $j$ and $w_{i}$ is the average wage in $i$. Iceberg commute costs are modeled as $d_{i j}=\exp \left(\kappa \tau_{i j}\right)$, where $\tau_{i j}$ is the average reported travel time in minutes between $i$ and $j$. We set $\kappa=0.01$, following micro-estimates from Ahlfeldt et al. (2015) and Tsivanidis (2022).
} 
and zone $j{ }^{31}$ Finally, $\xi_{j}$ is an unobserved location-specific "structural" utility shock, which may be correlated with price - we assume the variables in $X_{j}^{d}$ are exogenous. The shocks $\epsilon_{i j}$ are distributed i.i.d. type I extreme value. The utility of the outside option is normalized to zero, $u_{i 0}=0$.

Let $Z_{i}$ be a $C$-dimensional vector of household characteristics, including household size, age of the household head, a rental indicator, household income, and a college indicator for the household head. The heterogeneous demand parameters $\alpha_{i}^{d}$ and $\beta_{i}^{d}$ take the form:

$$
\left(\begin{array}{c}
\alpha_{i}^{d} \\
\beta_{i}^{d} \\
\gamma_{i}
\end{array}\right)=\left(\begin{array}{l}
\alpha^{d} \\
\beta^{d} \\
\gamma
\end{array}\right)+\Pi Z_{i}
$$

where $Z_{i}$ is the $C \times 1$ vector of demographic variables $z_{i, 1}, \ldots, z_{i, C}$ and $\Pi$ is a $(K+2) \times C$ matrix of coefficients containing: i) $\pi_{\alpha, 1} \ldots \pi_{\alpha, C}$, the interactions of price and each of the $C$ demographics in $Z_{i}$ ii) $\pi_{\gamma, 1} \ldots \pi_{\gamma, C}$, the interactions of travel time and each of the $C$ demographics in $Z_{i}$, and iii) $\pi_{\beta^{k}, 1} \ldots \pi_{\beta^{k}, C}$ for $1, \ldots, K$, the interactions of all of the demographic variables with all of the $K$ commuting zone characteristics.

We can then re-write utility separating out the parameters that only vary by neighborhood and the parameters that contain heterogeneity in preferences as follows:

$$
u_{i j}=\delta_{j}+\mu_{i j}+\epsilon_{i j}
$$

where $\delta_{j}=\alpha^{d} p_{j}+\beta^{d} X_{j}^{d}+\xi_{j}$ and $\mu_{i j}=\left(p_{j}, X_{j}^{d}, \tau_{i j}\right) \Pi Z_{i}+\gamma \tau_{i j}$.

Since we observe individual demographics, we can calculate the conditional choice probability that each individual $i$ chooses option $j$. Define $y_{i}$ as the choice indicator and $\theta^{d}$ as the vector of demand parameters. We have:

31. We model the travel time between living zone $j$ and working zone $k$ with a regression of the form

$$
\tau_{j k}=\mu+\eta \log \left(p o p_{j}\right)+f\left(d_{j k}, \phi\right)+v_{j k}
$$

where $\tau$ is the average reported travel time in minutes between the zones $j$ and $k, f$ is a flexible polynomial function of distance $d$ and regression parameters $\phi$, and $p o p_{j}$ is the number of households in zone $j$. Population is included in the model to allow for more dense areas to have longer travel times conditional on a distance to a given location. We estimate this equation on 30,934 route-level observations for which we observe any trip, using a cubic polynomial in distance. We then predict $\tau$ for all possible combinations of living zones in our model (329) and working zones reported in the data (517). There are more working zones than living zones because $i$ ) working zones include suburban zones, and ii) some survey respondents work in city zones where no-one in the survey lives and are thus dropped from the choice model. This predicted value then enters the utility equation in the estimation based on individual $i$ 's working zone, taken as fixed. 


$$
\operatorname{Pr}\left(y_{i}=j \mid Z_{i}, X, p, \xi, \theta^{d}\right)=\frac{\exp \left(\delta_{j}+\left(p_{j}, X_{j}^{d}, \tau_{i j}\right) \Pi Z_{i}+\gamma \tau_{i j}\right)}{1+\sum_{k \in J} \exp \left(\delta_{k}+\left(p_{k}, X_{k}^{d}, \tau_{i k}\right) \Pi Z_{i}+\gamma \tau_{i k}\right)}
$$

Note that the denominator of the conditional choice probability is taken over all locations in the city, implicitly assuming that all consumers choose from all possible neighborhoods in the city as well as the outside option 32

For estimation, we follow the standard two-step approach. In the first step, we use maximum likelihood to estimate heterogeneity parameters $\hat{\Pi}, \gamma$, and the fixed effects $\hat{\delta}_{j}$. The likelihood function is:

$$
L(\Pi, \delta \mid X, p, Z, \xi)=\prod_{i} \prod_{j \in J_{i}} \operatorname{Pr}\left(y_{i}=j \mid Z_{i}, X_{j}, p_{j}, \tau_{i j}, \xi, \Pi, \delta\right)
$$

In the second step, we can recover the level coefficients by estimating $\hat{\delta}_{j}=\alpha^{d} p_{j}+\beta^{d} X_{j}^{d}+\xi_{j}$ using an instrumental variables regression. We folow Bayer, Ferreira and McMillan (2007) and create instruments for price by taking the average housing and spatial characteristics within a geographic "donut" around the neighborhood centroid. These IVs follow the logic of betweenneighborhood competition: if location $j$ is surrounded by higher quality zones, then $j$ must lower its price to attract residents, implying a strong first stage. However, the nearest neighborhoods to $j$ may create direct quality spillovers, violating the exclusion restriction. As such they are excluded from the calculation, creating a "donut" around $j$ of neighborhoods that only influence the choice problem through their indirect impact on price in $j 3$

We follow Davis et al. (2021) in assuming exogeneity of neighborhood socio-demographics. While we allow households to have preferences over the pre-reform average demographic characteristic of neighborhoods, we do not allow for preferences over future demographic features of households who will move after the supply consequences of the reform. While this may be a restrictive assumption, below we show that the new extra housing units due to the reform represent a small fraction of the total housing stock, ruling out major demographic change. Moreover, as mentioned by Davis et al. (2021), this exogeneity assumption has two benefits: it avoids the search

\footnotetext{
32 In another version of the model, we restrict individual-specific choice sets choice set to the outside option and all of the locations in the consideration set $J_{i}$. To define this consideration set for each individual as all of the locations $j$ that are connected to $i$ 's location of work in the commuting matrix. In other words, we assume that, having decided where to work, individuals then make their housing location choice among the options allowed by their place of work. The results are similar and available upon request.

${ }^{33}$ We select our IVs from a set of neighborhood characteristics that includes the paved road share, RCMA, housing stock age, average units per building, and density and spatial characteristics that include the favela share of zone area, flood-zone share of zone area, average slope, and metro station presence. We include neighborhoods from 5-20 miles from $j$ in the average characteristics of competitors.
} 
for additional instruments for demographics, and it resolves the potential problem of multiple equilibria during the simulation exercise.

We estimate the model on a sample of 24,800 households with at least one employed member using the 2017 commuting survey data. To improve computational performance in the estimation routine, all variables are standardized by subtracting the mean value and dividing by the standard deviation across commuting zones. We estimate standard errors on all parameters by doublebootstrapping both the first and second stage of the estimation with 500 replications ${ }^{34}$

\subsubsection{Demand estimation results}

Table 4 presents our estimated demand parameters. The columns indicate the nine commuting zone characteristics (price, travel time, RCMA, age, units, density, paved, income and education) - summary statistics of the main demand variables are in Table A8. We allow demand for each characteristic to vary by the following individual demographics: household size, age, renter, income, and college degree. Bootstrapped standard errors are in parentheses. All demographics and neighborhood characteristics are standardized, so base coefficients are interpreted as the preference for a one standard deviation increase in the neighborhood characteristic for the demographically "average" household. The base coefficients are taken from column (9) in Table A9, which compares several different specifications of the demand-side IVs ${ }^{35}$

Focusing on these base coefficients, we find a negative elasticity of demand with respect to price and travel times. We find a positive elasticity with respect to RCMA, which implies that conditional on price and travel time to a given workplace, households prefer to live near areas with many high paying jobs. Regarding the built environment, we find consumers dislike old housing stock and also dislike greater density within a given building (units). However, they like denser neighborhoods (density) that have better infrastructure (paved). The base coefficient on income is negative and imprecise, suggesting there is an average preference for living in lower income

\footnotetext{
34 Bootstrap results for the price coefficients can be found in Figure A17. Distributions of estimates from the bootstrap procedure for other parameters look similar.

35 Table A9 shows results from different instrumental variable specifications. Column (1) presents the OLS estimate, column (2) includes only the average $X$ characteristics of competitors, column (3) includes only spatial characteristics, and column (4) includes both sets of IVs. Columns (5)-(9) contain different subsets of the most powerful IVs, as indicated in the Table footer. The price coefficient is smallest in the OLS regression, at 0.79 , and increases in magnitude to roughly 1.5-3.9 for the IV the different specifications. This downward bias in the OLS estimate of the price elasticity is consistent with the standard simultaneous equations bias in supply and demand systems. The IV specifications vary substantially in strength, with the strongest being the parsimonious single-IV specifications using RCMA and density in columns (5) and (6). Still, the price coefficients remain relatively stable across IV models. Since using multiple IVs increases the amount of information used for identification - although at the cost of first-stage power - our preferred specification in (9) uses the subset of four jointly strongest instruments: the favela share, slope, RCMA, and age.
} 
neighborhoods - the majority of residents in Sao Paulo are lower income. The base coefficient on education is positive, suggesting a preference for living in higher education neighborhoods.

The other rows in Table 4 present the coefficient estimate on the interaction term between the neighborhood characteristic in the column and the household characteristic in the row. For example, the negative coefficient -.185 on College degree in the first column indicates that the price elasticity of college graduates is more negative than that of the average household. Some interesting interactions between neighborhood characteristics and demographics are as follows. Higher income and college educated households appear to be more sensitive to price changes in this sample, and have somewhat greater taste for local density. As far as taste for number of units in the building, older, richer, and more educated households have greater dis-utility from living in buildings with greater units.

\subsection{Equilibrium}

With the estimated supply side parameters $\hat{\theta}^{s}$ and demand side parameters $\hat{\theta}^{d}$ in hand, we can solve for equilibrium in the residential housing market. Our counterfactual exercises will consist of imposing an exogenous zoning map $M$ (the densification policy experiment) and then solving the equilibrium to obtain $p(M)$, a $J$-vector of counterfactual prices $p=\left[p_{1}, \ldots, p_{J}\right]$ in each location $j$ such that supply and demand are equated under $M$. We conduct the equilibrium analysis at the commuting zone level. We analyze the following map $M$ scenarios: 1) A baseline equilibrium that takes observed zone-level market shares in 2016 (just prior to the 2016 reform), and estimated demand parameters and calculates the price vector necessary to equate supply and demand. 2) A counterfactual where we simulate the model for ten years given the 2004 zoning map. 3) A counterfactual where we simulate the model for ten years given the 2016 reform zoning map. 4) A "double BAR" counterfactual where we keep BAR at 2004 levels for blocks that in reality received lower BARs in the 2016 reform, and double the ultimate 2016 BAR for blocks that received an increase in BAR in the 2016 reform. In simulations (2)-(4) we run the supply model for 10 years to estimate long-run impacts of new housing supply on prices, residential sorting, and welfare.

To calculate the equilibrium prices for a given zoning map, we first take the estimated supply parameters $\hat{\theta}^{s}$ and use them to calculate $S_{j}\left(p ; M, X^{s}, \hat{\theta}^{s}\right)$, the market share of total housing supply in location $j$ for a given price vector, supply characteristics $X^{s}$, and zoning map $M$. Then, using the demand parameters $\hat{\theta}^{d}$, we calculate $D_{j}\left(p ; X^{d}, \hat{\theta}^{d}\right)$, the predicted market share of location $j$ given prices and the demand structure. The equilibrium condition is that supply equal demand in each 
commuting zone $J$ :

$$
S_{j}\left(p ; M, X^{s}, \hat{\theta}^{s}\right)=D_{j}\left(p ; X^{d}, \hat{\theta}^{d}\right) \forall j \in[1, \ldots, J]
$$

We obtain a system of $J$-equations in $J$ unknowns and search for the price vector $p$ that solves the equilibrium system of nonlinear equations.

To calculate the commuting zone-level demand shares $D_{j}\left(p ; X^{d}, \hat{\theta}^{d}\right)$, we must aggregate the individual conditional choice probabilities into commuting zone-level shares by integrating over the empirical distribution of demographics $F_{Z}$ :

$$
D_{j}\left(p, X^{d}, \hat{\theta}^{d}\right)=\int \operatorname{Pr}\left(y_{i t}=j \mid Z_{i}, X^{d}, p, \hat{\theta}^{d}\right) d F_{Z}
$$

Calculating the zone-level supply shares $S_{j}\left(p ; M, X^{s}, \hat{\theta}^{s}\right)$ is more complicated, since it requires solving two aggregation problems. First, our choice equation refers to new permits rather than the stock of buildings, so we must translate new building permits into market shares of total housing units. Second, our supply side equations are subprefeitura-quantile level and must be aggregated to the commuting zone level. For details on this aggregation procedure, see Appendix A.

Our equilibrium condition equates the market shares of each location as predicted by our estimated demand and supply models. Implicitly, this assumes that the population of the MSA will grow to meet the new housing stock built after a given shock to BAR. If this were not the case, then there would have to be real vacancies somewhere in the MSA after a positive housing supply shock in the model, since the total number of housing units would exceed the number of possible residents. In this sense, the equilibrium in shares is an "open city" model where new migrants are assumed to enter and fill in new vacancies. We believe that this is a more reasonable assumption for the city of Sao Paulo, which is the wealthiest city in Brazil and plays a somewhat similar role as that of New York City in the United States.

One potential criticism is that this "equilibrium in shares" assumption may be restrictive and lead us to underestimate price effects. An alternative assumption on the other extreme is that the São Paulo MSA is a closed economy, such that any counterfactual increases in housing supply in the city must be compensated by corresponding vacancies in the suburbs. This implies an equilibrium condition in levels, assuming no vacancies at $t=0$. For each counterfactual, we calculate equilibria under both the shares and levels assumptions and interpret these as upper and lower bounds, respectively, on the true counterfactual prices ${ }^{36}$

${ }^{36}$ To get a sense of migration patterns to Sao Paulo we looked at the fraction of 2010 census respondents who lived 


\subsection{Counterfactual Results}

\subsubsection{Equilibrium outcomes}

As a validation exercise, we begin by calculating the implied prices that equate the observed commuting-zone market shares (supply) and estimated demand (based on our demand model) just prior to the 2016 reform (the "baseline scenario"). The purpose here is to get a sense of how well the equilibrium model implied prices can replicate observed listing prices when using our equilibrium calculation procedure. Figure A23 shows the correlation between model-predicted prices for the baseline scenario and the observed listing price data from Properati. Our model prices do a good job of replicating the observed market prices, with an $R^{2}=0.75$. Figure A24 similarly plots the observed demographic composition of zones (log of average income and share of household heads with college education) in the data against the demographics that would be predicted by the individual-level choice probabilities of the model at baseline. The $R^{2}$ are 0.89 and 0.96 for log income and college-educated share, respectively.

Table 5 presents the main zone-level results on prices and quantities from our simulations. All of the results show model simulated outcomes ten years after 2016. Column 1 presents simulated equilibrium outcomes assuming the 2004 zoning stayed in place from 2016 to 2026, with an average max BAR of 1.55. Column 2 presents results for a simulation where zoning is changed according to the 2016 reform map in 2016, with a higher max BAR of 2.09. Column 3, the "Double BAR scenario" keeps BAR at the 2004 level for those blocks that had a BAR decrease in the 2016 reform, and doubles post-2016 reform BAR for all blocks that received a BAR increase in the 2016 reform. Even under the Double BAR scenario, the average max BAR in the city is still just 3.49, which is substantially lower than the BAR levels observed in the most permissive zoning regimes in the world. For example, Singapore has many blocks allowing BAR levels in the 8 to 10 range.

Row 1 of each panel gives the total new units that are created within the city in 10 years as a result of the corresponding zoning policy; the totals exclude units created as a result of the citywide growth trend. Row 2 shows the share of the total within city stock that the new units in row

outside of the municipality as of 2005. Only $3.56 \%$ of Sao Paulo city residents report having lived outside of Sao Paulo metropolitan area as of 2005 (average annual in-migration rate of .71\%). Among those recent migrants, 17.6\% have a college degree, which is approximately $4 \%$ higher than the average college degree holding rate. The average income of these migrants is $\mathrm{R} \$ 900$ reals per month, which is $10 \%$ less than the Sao Paulo city average. An even smaller share, $.35 \%$ of Sao Paulo city residents, report living in the suburbs as of 2005 . These migrants from the suburbs are 17 percentage points more likely to have gone to college and earn approximately $\mathrm{R} \$ 600$ more per month. To summarize, the 2005 to 2010 migration to Sao Paulo is small, mostly comes from outside of the metropolitan area, and the average characteristics are similar to the Sao Paulo city as a whole. Given those numbers, we also assume in our simulations that the new households migrating from new construction will reflect the demographics of the city as a whole. 
1 represent. In Panel A, relative to a 10 year continuation of the 2004 zoning rules (Column 1), the model predicts that the 2016 zoning reform will produce approximately 47,030 net new housing units, or an approximate 1.9 percent increase in the housing stock of the city. The relatively small aggregate effect on the supply of housing is consistent with the fact the average BAR in the city only increased by 0.54 , and did not change or was reduced in $48 \%$ of city blocks. In Column 3 we see that in the Double BAR reform scenario the housing stock in São Paulo increases by 27.5\% relative to the 2004 zoning reform.

Row 3 gives the model-predicted average zone-level price in thousands of reais per square meter. Prices are similar in Columns 1 and 2, falling by only $0.5 \%$ on average, indicating that the 2016 reform has small impacts on average housing prices in São Paulo. Even under the Double BAR scenario we estimate only a $7.5 \%$ decrease in prices on average. One reason the price effects are small is that the suburbs are assumed to grow at an annual rate $(1.7 \%)$ that is faster than the city $(1 \%)$; so although the increase in housing units in the city is large relative to the stock of city housing, the supply increase relative to the total metropolitan area is smaller and therefore the price response is also commensurately smaller ${ }^{37}$ Another reason is that we assume each unit vacated in favor of a newly constructed unit is filled by a new migrant to the MSA, dampening downward pressure on prices. But if we assume instead that the MSA is a closed economy, as in Panel B, we see substantially larger price reductions from the 2016 and Double BAR scenarios, at $1.1 \%$ and $15.5 \%$, respectively, even as the equilibrium unit increase is somewhat smaller.

Row 4 shows that the reform produces only a small change in the share of households living in the city versus the suburbs. This small change is unlikely to impact city neighborhood demographics. We verify this assumption in the simulation by calculating the implied demographic characteristics given the predicted demand side choice probabilities. Figure A25 compares demographics for city vs. suburbs under different scenarios. At baseline, the suburbs are lower income and less educated, and the 2016 zoning reform does not change the differences between city and suburbs. Only the more dramatic Double BAR reform influences neighborhood demographics by attracting more lower income and lower education residents from the suburbs to the city.

Figure 9 shows that, while there is only a small aggregate effect of the 2016 reform - consistent with the small overall change in the housing shock, there is substantial heterogeneity across the city, mostly predicted by where BAR changed most. Figure 9 plots the distribution of zone-level

37In the model, we account for differential secular trends in housing growth in the city vs. the suburbs using annualized growth rates from 2000-2010, calculated from Brazil's housing census. See Appendix A for details on how these rates enter the supply aggregation equation. 
changes in prices and units, and then correlates them with the average BAR change within a commuting zone. As expected, places with larger BAR shocks see more construction and lower prices. Quantitatively, the largest price reductions are roughly $\mathrm{R} \$ 341$ reais per meter squared, or around $4.6 \%$ of that zone's market price under the 2004 counterfactual. The largest supply shocks are approximately 1549 additional units, or around $17.1 \%$ of that zone's housing stock under the 2004 counterfactual. If instead we solve for equilibrium in levels, we find that the largest price effects are around $5.4 \%$ of the zone's price under the 2004 counterfactual. These estimates are qualitatively similar to the medium-run reduced form results presented in Section 5.4 .

Figure A26 maps the BAR change in the 2016 reform, as well as the model simulated predictions for changes in the number of housing units, prices, and market shares. BAR changes were larger in more outlying areas of the city, rather than in the denser core where BAR actually fell in many cases. As such, these more outlying areas saw lower prices and gained market share in a way that maps directly on to the BAR change.

\subsubsection{Welfare analysis}

Table 6 presents our estimates of the 10 year welfare impacts of the 2016 reform and Double BAR scenarios relative to a continuation of the 2004 zoning policy ${ }^{38}$ The estimates in the table give per-household average consumer surplus gains in reais, except the bottom row which gives MSA-wide aggregate gains in millions of reais ${ }^{39}$ In columns (1) and (4) we update only the prices in calculating welfare in the new equilibrium, while in columns (2) and (5) we update prices and the features of the built environment - the average age of buildings, average units per building, and neighborhood density - based on the supply shock. Focusing first on column (1), our model predicts an unequal distribution of surplus across demographic groups. The average college educated household has an estimated gain relative to the 2004 zoning regime of $\mathrm{R} \$ 39.56$ over ten years (approximately \$12.27 USD in total at 2016 exchange rates), and the highest income quintile has a similar R\$36.15 gain after ten years. High income and college groups are more price sensitive in our demand model, and therefore obtain the largest gains from the new housing supply. The aggregate welfare gains over 10 years are $\mathrm{R} \$ 136.44$ million reais, or about $\$ 42.3$ million USD.

Column (2) shows there is approximately 4.3 times larger consumer surplus gains when we

\footnotetext{
38 Table A14 presents corresponding results for the equilibrium in levels.

${ }^{39}$ Consumer surplus is calculated as the "inclusive value," also know as the logsum, from Small and Rosen (1981), which gives the ex-ante expected value of a utility-maximizing choice for consumer $i$, normalized by the individualspecific price coefficient.
} 
allow welfare to respond to changes in the built environment induced by the 2016 zoning reform. The aggregate welfare gain rises to $\mathrm{R} \$ 581.56$ million, or about $\$ 183.1$ million USD. This is primarily because density increases and the age of housing units falls. These results suggest that most of the value of zoning comes through the presence of a newer housing stock and greater density, as opposed to price reductions. In Table A15 we decompose the effect of each housing characteristic and confirm that age and density are the largest contributors to these welfare gains. Interestingly, the unequal distribution of surplus across income quintiles actually narrows slightly once we incorporate changes in neighborhood characteristics, because poorer households have a greater taste for newer units. Inequality also emerges between renters and owners after updating $X$ because owners prefer newer buildings. After accounting for effects on housing characteristics, the Double BAR scenario in column (5) produces much larger consumer surplus gains, at $\mathrm{R} \$ 2,188.10$ reais ( $\$ 679.16$ USD) per household, or R $\$ 11.73$ billion ( $\$ 3.64$ billion USD) in aggregate. Columns (3) and (6) account for the role of increased congestion arising from greater densification, given households' disutility of commuting time. Congestion costs erode the aggregate welfare gains by $1.3 \%$ and $2.6 \%$ for the 2016 reform and the Double BAR scenario, respectively 40

The results above described changes in welfare for households in the Sao Paulo metropolitan area, according to their expected value of all neighborhood options. However, zoning reforms present other costs and benefits that may influence the political passage of such densification measures. In Table 7 we show aggregate estimates for five additional measures of costs and benefits: changes in nominal housing wealth for existing homeowners and landlords, changes in developer profits, welfare gains for new residents, and changes in city productivity. The first row of Table 7 reprints the final aggregate welfare gain estimates from Table 6 for the equalizing shares equilibrium. The second and third rows show how housing wealth varies by type of reform relative to the 2004 policy status quo. Our simulation predicts that homeowners and landlords will face nominal house price losses of $\mathrm{R} \$ 11.11$ and $\mathrm{R} \$ 3.89$ billions due to the 2016 reform, respectively. Together, these losses are much larger than the welfare gain of $\$ 0.67$ billion due to more housing options, and can partially explain why existing real estate owners fear zoning reforms that promote more densification 41 The contrast between changes in house values and welfare is even higher for the

\footnotetext{
40 Appendix Figure A27 displays individual-level changes in expected commuting time and decomposes these changes into location and population effects.

41 One important caveat with such housing wealth losses is that housing consumption does not change as house prices fall. Moreover, homeowners are always able to sell their existing homes and buy other houses of similar quality given that price drops occur across the city. Landlords, on the other hand, mostly care about returns on their investment, so the nominal losses represent real reductions in profits.
} 
Double BAR scenario, given the larger price effects.

On the other hand, row 4 shows that developer profits increase by approximately $\mathrm{R} \$ 4.47$ billion 42 The aggregate losses to local homeowners are larger than the gains to developers, suggesting that if lobbying efforts for zoning reform are proportional to the potential gains/losses from the zoning, cities around the globe would be unlikely to approve a zoning reform similar to the one implemented in Sao Paulo, much less a Double BAR style reform. Row 5 shows potential welfare gains for new residents, given that more housing allows the migration of new households 43 Given the relatively small number of extra new houses built because of the 2016 reform, the aggregate consumption gains from new residents is also small. Gains for new residents become sizeable only in the Double BAR scenario, as a much larger number of people can now move to the city.

Finally, the last row shows a back-of-the envelope calculation of the potential effect of zoning reform on productivity. For this exercise we heavily rely on the estimates of Glaeser and Gyourko (2018) ${ }^{44}$ We find that future gains in productivity could be $\mathrm{R} \$ 0.92$ billion, and are another potential justification for increasing densification.

\section{Conclusion}

The impact of zoning on housing markets was one of the most important and hotly debated subjects prior to the Covid-19 pandemic, and is likely to regain its status as the pandemic ebbs and increases in cost of living return to the forefront of household worries. In this paper we contribute to the literature by studying the impact of a 2016 zoning reform in São Paulo that increased the ability of developers to supply housing units by lifting limitations on permitted densification on a block-by-block basis. Using a spatial discontinuity design and the timing of the reform, we find that developers responded swiftly to obtain approximately 65 percent more permits in blocks that relaxed zoning rules. In the medium-run, the reform increased availability of homes for sale and reduced prices in neighborhoods with larger increases in allowed densification.

We also develop a framework to estimate welfare of local residents by integrating the spatial

\footnotetext{
42 Predicted developer profits are calculated as the total value of new developed housing units times a mark up of $10 \%$ which is a conservative estimate of mark ups for real estate development.

43 For this calculation we use the conservative assumption that new residents, on average, would have the same welfare benefit as that of existing residents.

44 Glaeser and Gyourko (2018) find that a dramatic zoning reform across all cities in the United States - that allow the movement of enough workers to equalize wages across all cities - would generate a GDP gain of $2 \%$. Assuming Sao Paulo in Brazil plays an analogous role in the Brazilian economy as that of New York city in the United States economy, and also accounting for the relative magnitude of new housing developed due to the 2016 reform in Sao Paulo, we can back out potential productivity gains. See Online Appendix for details of the calculation.
} 
RD design in to a supply and demand model of residential housing, effectively endogeneizing housing regulation. With this model we can estimate structural demand and supply parameters, and then simulate ten year forward outcomes of prices, built environment, and welfare. Our framework accounts for both costs and benefits of densification, which allows for a more complex picture of the effects of zoning reforms.

We find mild aggregate price and supply changes due to the fact the aggregate supply response induced by the 2016 reform is small relative to the São Paulo housing stock. However, we find that certain neighborhoods that allowed for more densification had larger increases in supply and bigger reductions in prices, i.e., improved affordability. Our welfare analysis suggests that higher income and education groups benefit the most from the reform, due to their greater price sensitivity and the ability to move from the suburbs to areas in the city that are closer to workplaces. Moreover, welfare gains are four times larger when accounting for changes in the built environment of the city, especially with respect to neighborhood density and age of buildings. This suggests a fair amount of the economic value of zoning reforms comes through the presence of newer housing stock, as opposed to lower prices. We also show that more aggressive zoning reforms produce much larger welfare gains. Finally, we show that such reforms negatively impact the housing wealth of existing homeowners and landlords, which may generate political backlash in the form of NIMBYism.

\section{References}

Ahlfeldt, Gabriel M, Stephen J Redding, Daniel M Sturm and Nikolaus Wolf. 2015. “The Economics of Density: Evidence from the Berlin Wall." Econometrica 83(6):2127-2189.

Allen, Treb, Costas Arkolakis and Xiangliang Li. 2016. “Optimal City Structure.” Dartmouth College, working paper.

Ashar, Sandeep. 2018. "Mumbai: Plan for Taller Buildings, Higher Densities Around Metro, Rail Corridors on Hold." Indian Express, https://indianexpress.com/article/cities/mumbai/mumbai-planfor-taller-buildings-higher-densities-around-metro-rail-corridors-on-hold-5333536/.

Balboni, Clare, Gharad Bryan, Melanie Morten and Bilal Siddiqi. 2020. “Transportation, Gentrification, and Urban Mobility: The Inequality Effects of Place-Based Policies." Stanford University, working paper. 
Baum-Snow, Nathaniel and Lu Han. 2022. "The Microgeography of Housing Supply." University of Toronto, working paper.

Bayer, Patrick, Fernando Ferreira and Robert McMillan. 2007. “A Unified Framework for Measuring preferences for Schools and Neighborhoods." Journal of Political Economy 115(4):588-638.

Berry, Steven, James Levinsohn and Ariel Pakes. 1995. “Automobile Prices in Market Equilibrium." Econometrica 63(4):841-890.

Brueckner, Jan K and Kala Seetharam Sridhar. 2012. "Measuring Welfare Gains from Relaxation of Land-Use Restrictions: The Case of India's Building-Height Limits." Regional Science and Urban Economics 42(6):1061-1067.

Brueckner, Jan K and Ruchi Singh. 2020. "Stringency of land-use regulation: Building heights in US cities." Journal of Urban Economics 116:103239.

Brueckner, Jan K and Somik V Lall. 2015. “Cities in Developing Countries: Fueled by Rural-Urban Migration, Lacking in Tenure Security, and Short of Affordable Housing." Handbook of Regional and Urban Economics 5:1399-1455.

Bryan, Gharad, Jonathan De Quidt, Tom Wilkening and Nitin Yadav. 2017. Land Trade and Development: A Market Design Approach. Technical report CEPR Discussion Paper No. DP12136.

Calder-Wang, Sophie. 2022. "The Distributional Impact of the Sharing Economy on the Housing Market." University of Pennsylvania, working paper .

Combes, Pierre-Philippe, Gilles Duranton and Laurent Gobillon. 2021. "The Production Function for Housing: Evidence from France." Journal of Political Economy 129(10):2766-2816.

Davis, Morris, Jesse Gregory, Daniel Hartley and Kegon Tan. 2021. “Neighborhood Effects and Housing Vouchers." Quantitative Economics 12(4):1307-1346.

Diamond, Rebecca and Tim McQuade. 2019. "Who Wants Affordable Housing in Their Backyard? An Equilibrium Analysis of Low-Income Property Development." Journal of Political Economy 127(3):1063-1117.

Ding, Chengri. 2013. “Building Height Restrictions, Land Development and Economic Costs." Land Use Policy 30(1):485-495. 
Dougherty, Conor. 2020. "California, Mired in a Housing Crisis, Rejects an Effort to Ease It." New York Times, https://www.nytimes.com/2020/01/30/business/economy/sb50-california-housing.html .

Duranton, Gilles and Diego Puga. 2020. “The Economics of Urban Density." Journal of Economic Perspectives 34(3):3-26.

Epple, Dennis, Brett Gordon and Holger Sieg. 2010. “A New Approach to Estimating the Production Function for Housing." American Economic Review 100(3):905-24.

Fujita, M. 1989. Urban economic theory: Land use and city size. Cambridge University Press.

Fujita, M. and H. Ogawa. 1982. "Multiple equilibria and structural transition of non-monocentric urban configurations." Regional Science and Urban Economics 12(2):161-196.

Ganong, Peter and Daniel Shoag. 2017. "Why Has Regional Income Convergence in the U.S. Declined?" Journal of Urban Economics 102:76-90.

Giaquinto, Paulo Ricardo et al. 2010. "Planos diretores estratégicos de São Paulo, nova roupagem velhos modelos." Universidade Presbiteriana Mackenzie, working paper .

Glaeser, Edward and Joseph Gyourko. 2018. "The Economic Implications of Housing Supply." Journal of Economic Perspectives 32(1):3-30.

Glaeser, Edward L, Joseph Gyourko and Raven E Saks. 2005. “Why Have Housing Prices Gone Up?" American Economic Review 95(2):329-333.

Goldsmith-Pinkham, Paul, Isaac Sorkin and Henry Swift. 2020. "Bartik instruments: What, when, why, and how." American Economic Review 110(8):2586-2624.

Gyourko, Joseph, Jonathan Hartley and Jacob Krimmel. 2021. “The Local Residential Land Use Regulatory Environment Across US Housing Markets: Evidence from a New Wharton Index." Journal of Urban Economics 124:103337.

Gyourko, Joseph and Raven Molloy. 2015. "Regulation and Housing Supply." Handbook of Regional and Urban Economics 5:1289-1337.

Harari, Mariaflavia. 2020. "Cities in Bad Shape: Urban Geometry in India." American Economic Review 110(8):2377-2421. 
Hsieh, Chang-Tai and Enrico Moretti. 2019. "Housing Constraints and Spatial Misallocation." American Economic Journal: Macroeconomics 11(2):1-39.

Kulka, Amrita. 2019. "Sorting into neighborhoods: The role of minimum lot sizes." University of Warwick, working paper .

Kulka, Amrita, Aradhya Sood and Nicholas Chiumenti. 2022. "How to Increase Housing Affordability? Understanding Local Deterrents to Building Multifamily Housing." Federal Reserve Bank of Boston Research Department Working Papers 22(10).

Lucas, Robert and Esteban Rossi-Hansberg. 2002. "On the Internal Structure of Cities." Econometrica 70(4):1445-1476.

Mullahy, John. 1997. “Instrumental-Variable Estimation of Count Data Models: Applications to Models of Cigarette Smoking Behavior." Review of Economics and Statistics 79(4):586-593.

Murphy, Alvin. 2018. "A Dynamic Model of Housing Supply." American Economic Journal: Economic Policy 10(4):243-67.

Paciorek, Andrew. 2013. "Supply Constraints and Housing Market Dynamics." Journal of Urban Economics 77:11-26.

Rossi-Hansberg, Esteban and Stephen Redding. 2017. “Quantitative spatial economics.” Annual Review of Economics 9:21-58.

Saconi, Rose and Carlos Entini. 2013. Como era São Paulo sem Plano Diretor. Technical report. Accessed: 2021-04-07.

Saiz, Albert. 2010. “The Geographic Determinants of Housing Supply." Quarterly Journal of Economics 125(3):1253-1296.

Small, Kenneth A. and Harvey S. Rosen. 1981. "Applied Welfare Economics with Discrete Choice Models." Econometrica 49(1):105-130.

Song, Jaehee. 2021. “The Effects of Residential Zoning in US Housing Markets." University of Colorado Boulder, working paper. Available at SSRN 3996483.

Tabarrok, Alex and Tyler Cowen. 2018. Skyscrapers and Slums: What's Driving Mumbai's Housing Crisis? Technical report Marginal Revolution University. 
Trounstine, Jessica. 2018. Segregation by Design: Local Politics and Inequality in American Cities. Cambridge University Press.

Tsivanidis, Nick. 2022. "Evaluating the Impact of Urban Transit Infrastructure: Evidence from Bogota's TransMilenio." University of California Berkeley, working paper .

Turner, Matthew A, Andrew Haughwout and Wilbert Van Der Klaauw. 2014. "Land use regulation and welfare." Econometrica 82(4):1341-1403. 


\section{Figures}

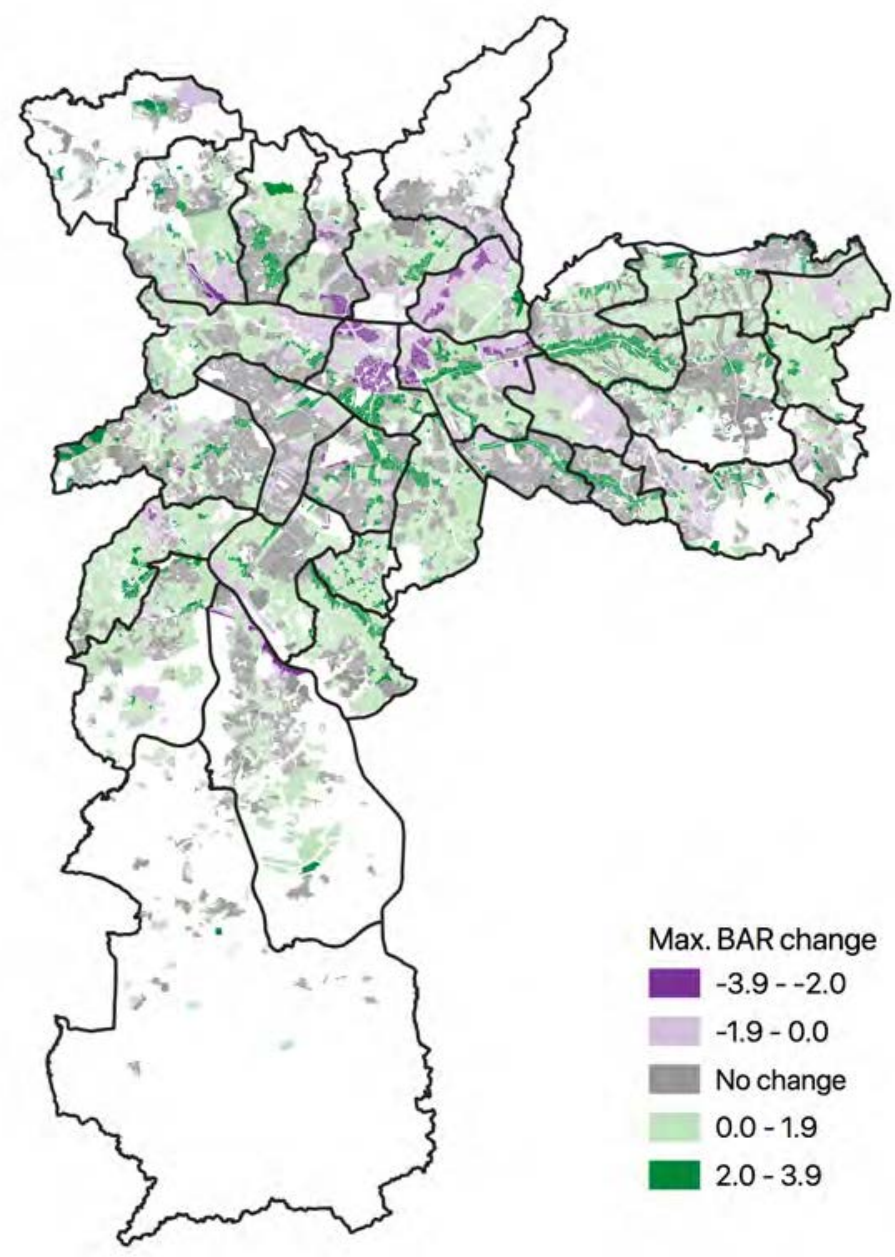

Figure 1: Map of Change in Maximum Allowed Built Area Ratio (BAR) from 2004 to 2016 Zoning Regime 


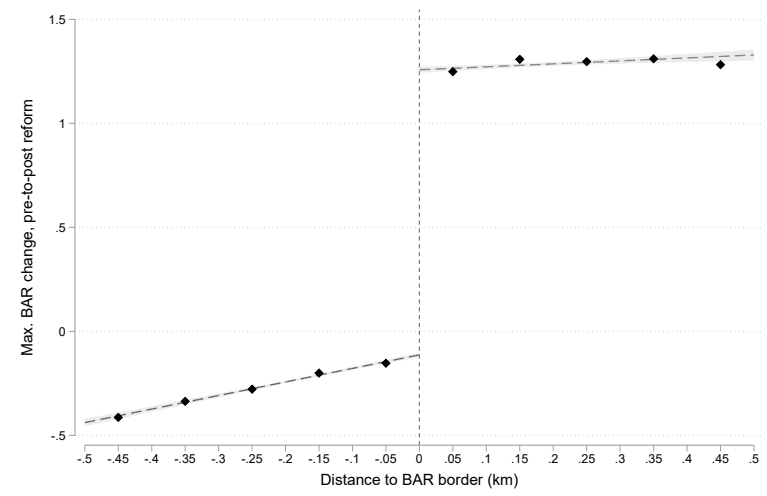

Figure 2: Built Area Ratio Change, Pre-to-Post 2016 Reform

This figure plots the change in the max BAR allowed for blocks within a .1 kilometer bin of our running variable. Control blocks are to the left of the dashed vertical line; treatment blocks are to the right. For control (treatment) blocks the running variable is the distance to the nearest treatment (control) block. A treatment block is defined as a block whose max BAR increased in the 2016 reform. Control blocks are those whose max BAR declined or stayed the same in the 2016 reform. See Appendix Figure A9 for this figure using only control blocks whose max BAR stayed the same.

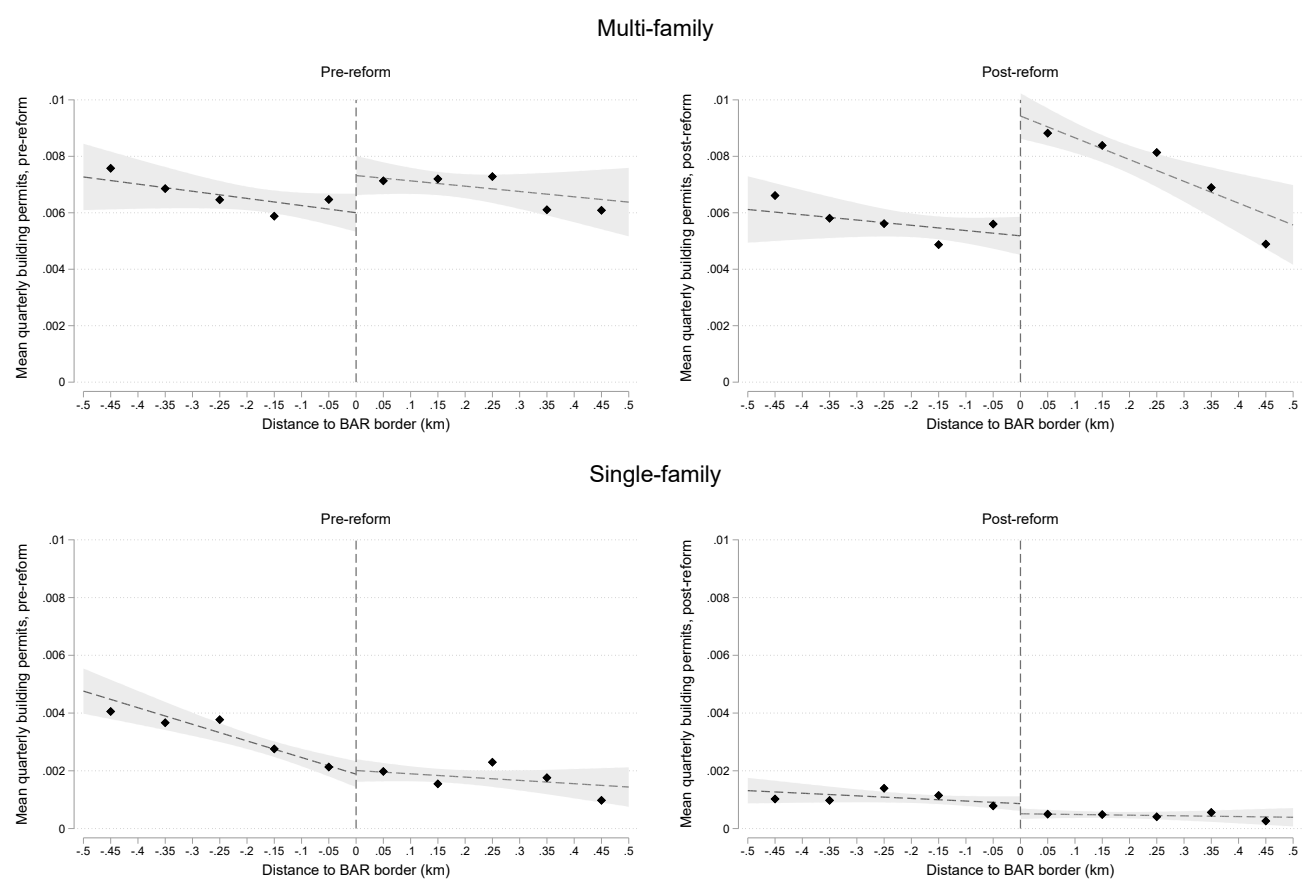

Figure 3: Multi-Family vs. Single-Family Permit Filings

This figure plots mean quarterly building permits issued for blocks within a $.1 \mathrm{~km}$ bin of our running variable. Control blocks are to the left of the dashed vertical line; treatment blocks are to the right. For control (treatment) blocks the running variable is the distance to the nearest treatment (control) block. A treatment block is defined as a block whose max BAR increased in the 2016 reform. Control blocks are those whose max BAR declined or stayed the same in the 2016 reform. Pre-reform is 2012Q2 - 2016Q1 and post-reform is 2016Q2 - 2019Q4. 


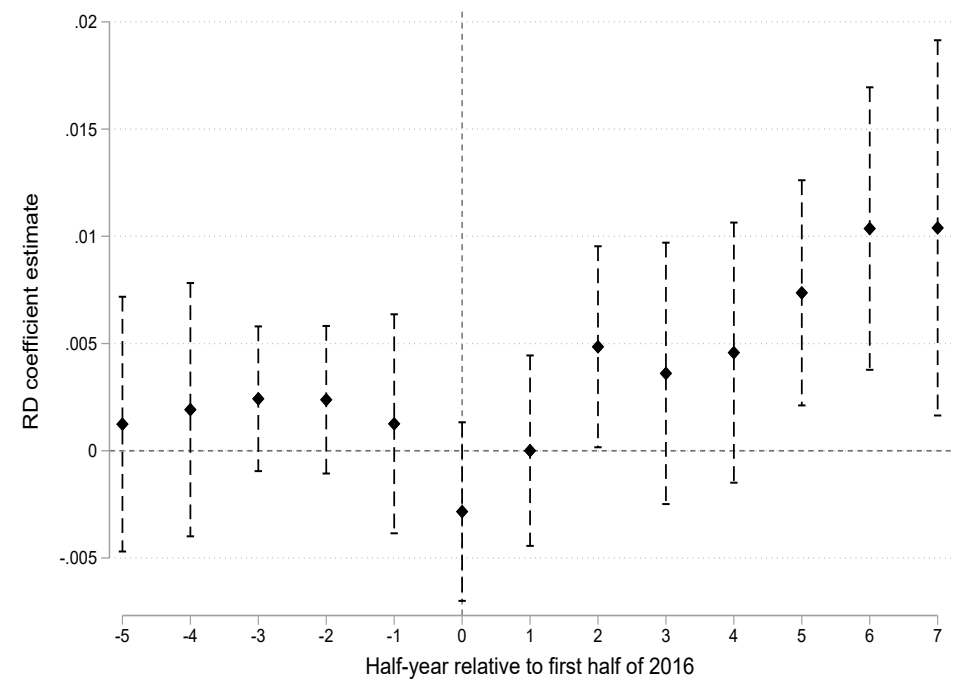

Figure 4: Dynamic RD coefficients for multifamily permit filings

This figure plots the regression-discontinuity coefficients separately estimated for half-years around the reform. The estimates come from a linear specification as in Column (2) of Table 2 with sub-prefeitura fixed effects.
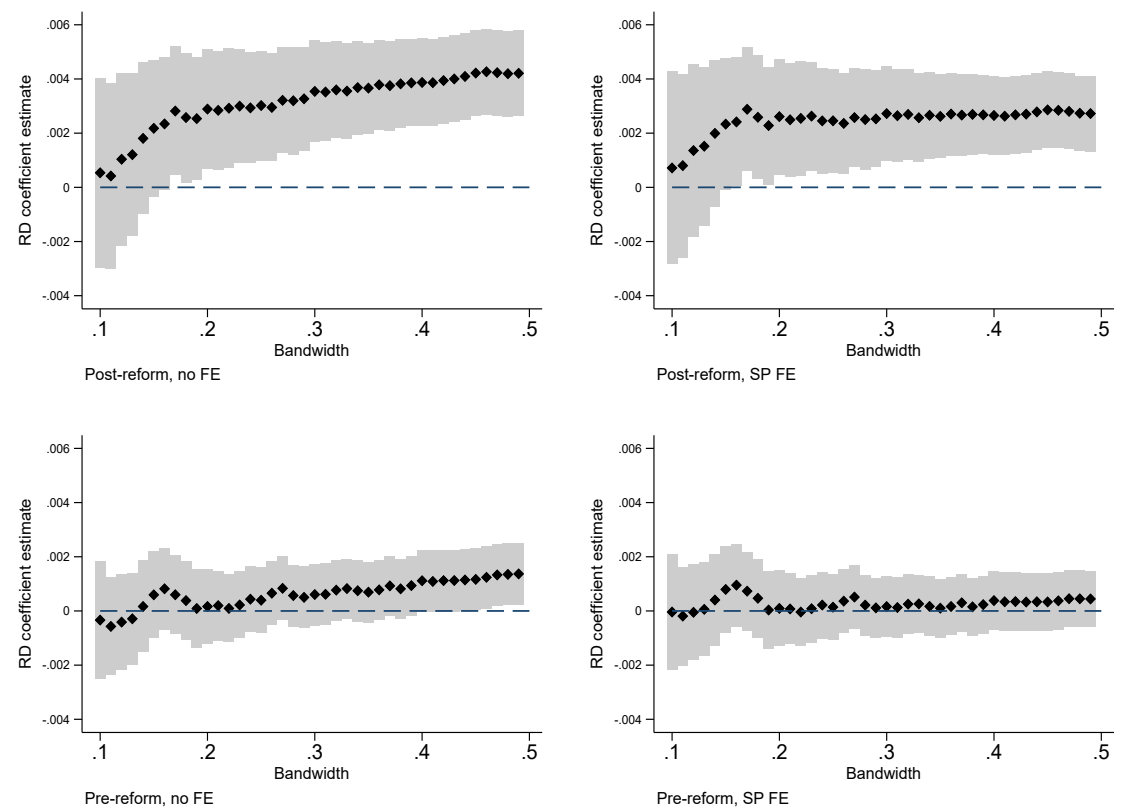

Figure 5: Multi-Family Permit Fillings by Bandwidth of Running Variable

This figure shows RD coefficient estimates with a linear specification considering larger windows around the cut-off (bandwidths). The outcome variable is quarterly filed building permits. The pre-reform period includes quarters 2012Q2-2016Q1; the post-reform period includes quarters 2016Q2-2019Q4. SP FE indicates subprefeitura fixed effects. Standard errors clustered at commuting zone level. 


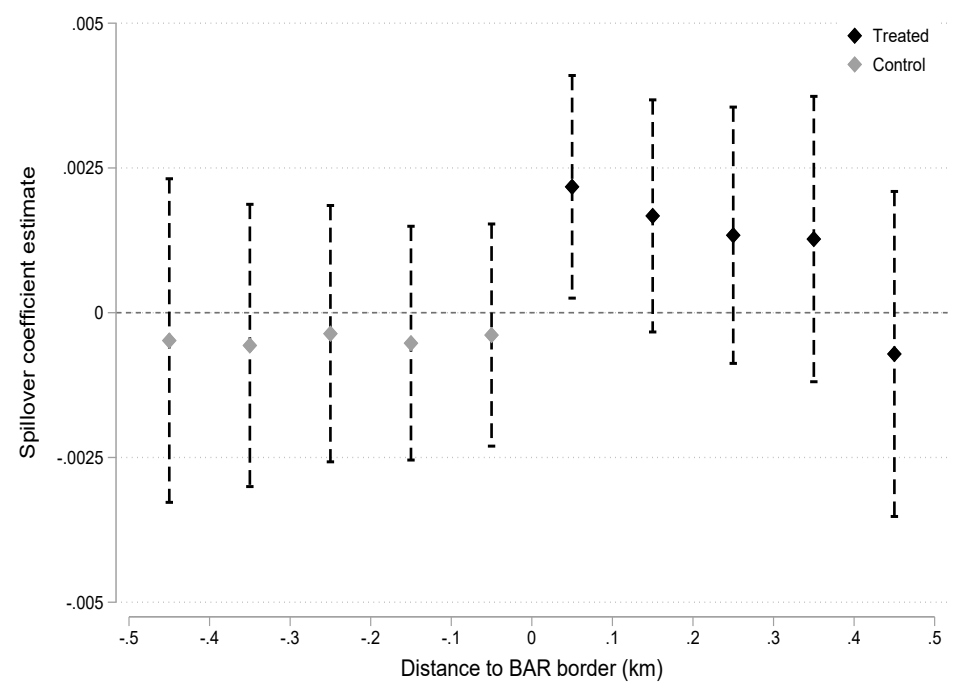

Figure 6: Estimates of Spillover Effects

This figure reports regression coefficients on the interaction between the treatment status of a block with its distance to the nearest opposite status block; the omitted group are control blocks that are $.5 \mathrm{~km}$ away from the nearest treatment block. See regression equation 2 for underlying specification.

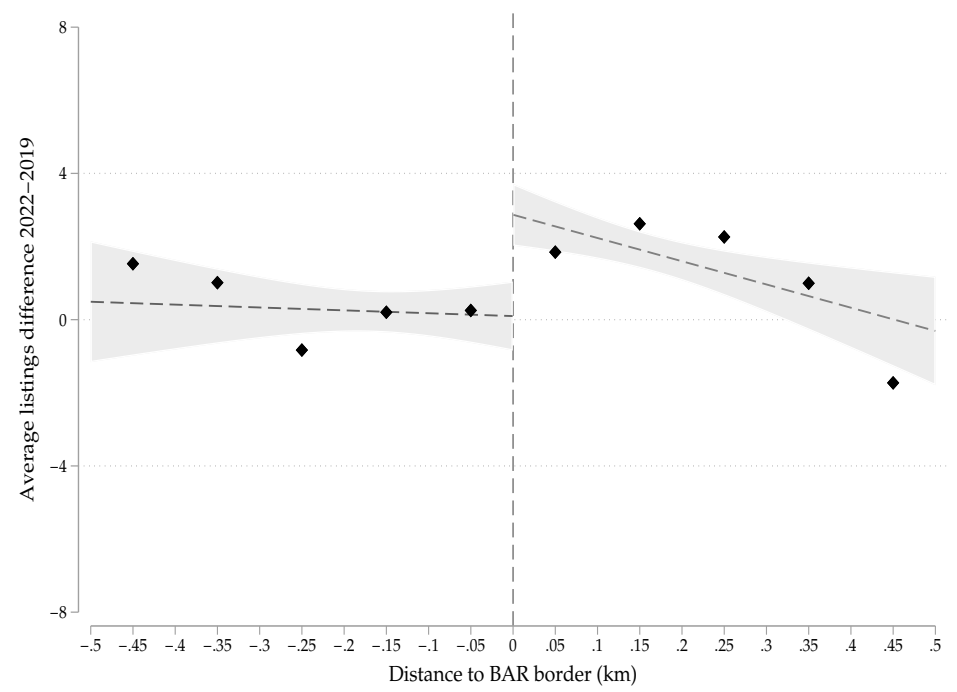

Figure 7: Listings Difference 2022-2019

This figure plots average 2022-2019 difference in number real estate of listings for sale for blocks within a $.1 \mathrm{~km}$ bin of our running variable. Control blocks are to the left of the dashed vertical line; treatment blocks are to the right. For control (treatment) blocks the running variable is the distance to the nearest treatment (control) block. A treatment block is defined as a block whose max BAR increased in the 2016 reform. Control blocks are those whose max BAR declined or stayed the same in the 2016 reform. 

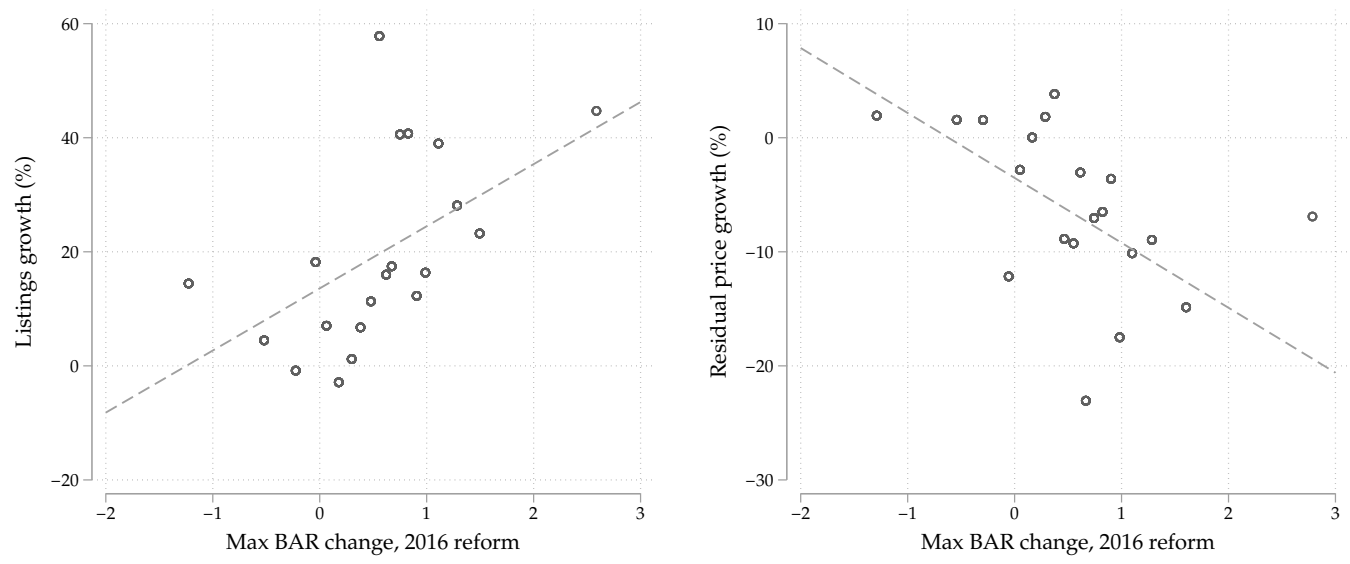

Figure 8: Growth in listings and residual prices 2022-2019

The left side figure shows a bin-scatter of commuting zone level listings growth against the average max BAR increase in the 2016 reform. The right side shows the same bin-scatter, with the y-variable changed to growth in average residual price within the commuting zone. Growth rates are for 2022 relative to 2019.
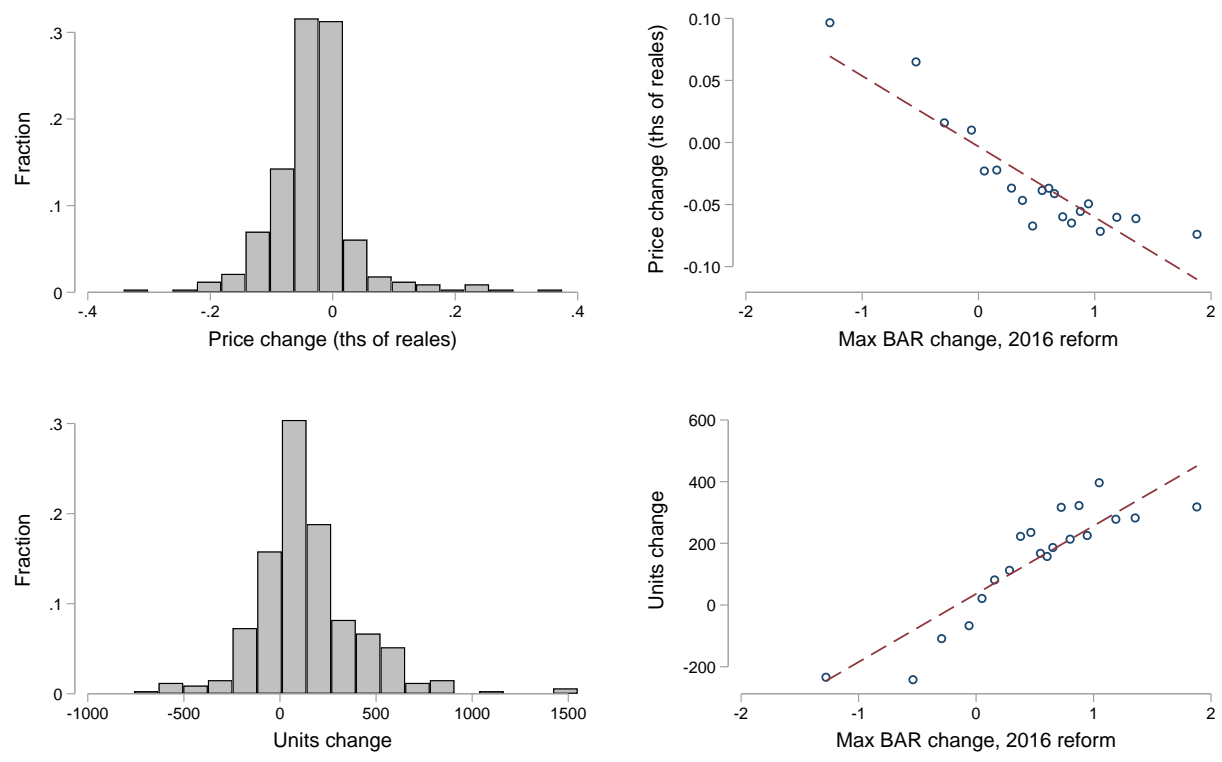

All changes relative to 2004 reform

Figure 9: Equilibrium changes under the 2016 reform

The top-left figure shows the distribution, across commuting zones, of 2016 reform model simulated price changes relative to a continuation of the 2004 zoning regime. The bottom-left figure shows the same for number of housing unit changes. The top-right figure shows a bin-scatter of the 2016 reform model predicted commuting zone level price change against the average max BAR increase in the 2016 reform. The bottom-right shows the same bin-scatter, with the $y$-variable changes to increase in number of housing units within the commuting zone. 


\section{Tables}

Table 1: RD First stage

\begin{tabular}{lcccc}
\hline \hline \multirow{2}{*}{ Outcome } & \multicolumn{4}{c}{ max BAR change } \\
\cline { 2 - 5 } & $(1)$ & $(2)$ & $(3)$ & $(4)$ \\
\hline Panel A: No sub-prefeitura FE & & & & \\
\hline Treat BAR & $1.519^{* * *}$ & $1.426^{* * *}$ & $1.365^{* * *}$ & $1.354^{* * *}$ \\
& $(0.029)$ & $(0.029)$ & $(0.031)$ & $(0.031)$ \\
Specification & Base & Linear & Quadratic & Cubic \\
Observations & 43231 & 43231 & 43231 & 43231 \\
Mean of Dep. Variable & -0.153 & -0.153 & -0.153 & -0.153 \\
& & & & \\
Panel B: With sub-prefeitura FE & & & & \\
\hline Treat BAR & $1.516^{* * *}$ & $1.453^{* * *}$ & $1.386^{* * *}$ & $1.355^{* * *}$ \\
& $(0.025)$ & $(0.027)$ & $(0.029)$ & $(0.030)$ \\
Specification & Base & Linear & Quadratic & Cubic \\
Observations & 43225 & 43225 & 43225 & 43225 \\
Mean of Dep. Variable & -0.153 & -0.153 & -0.153 & -0.153 \\
\hline
\end{tabular}

Standard errors clustered by commuting zones in parentheses. Specification refers to the order of the polynomial for the running variable, which is distance to the RD boundary. The polynomial is always interacted with the treatment indicator. Sample is all city blocks with zoning information. Mean of dependent variable calculated for control blocks within $0.1 \mathrm{~km}$ of the BAR boundary. ${ }^{*} p<0.05$, ** $p<0.01,{ }^{* * *} p<0.001$.

Table 2: RD reduced form

\begin{tabular}{lcccc}
\hline \hline Outcome & \multicolumn{4}{c}{ New multi-family building permits } \\
\cline { 2 - 5 } & $(1)$ & $(2)$ & $(3)$ & $(4)$ \\
\hline Panel A: No sub-prefeitura FE & & & & \\
\hline Treat BAR & $0.00170^{*}$ & $0.00409^{* * *}$ & $0.00481^{* * *}$ & $0.00428^{* * *}$ \\
& $(0.00071)$ & $(0.00073)$ & $(0.00078)$ & $(0.00086)$ \\
Specification & Base & Linear & Quadratic & Cubic \\
Observations & 43231 & 43231 & 43231 & 43231 \\
Mean of Dep. Variable & 0.00560 & 0.00560 & 0.00560 & 0.00560 \\
& & & & \\
Panel B: With sub-prefeitura FE & \multicolumn{4}{c}{} \\
\hline Treat BAR & $0.00198^{* * *}$ & $0.00228^{* * *}$ & $0.00268^{* * *}$ & $0.00313^{* * *}$ \\
Specification & $(0.00052)$ & $(0.00056)$ & $(0.00066)$ & $(0.00080)$ \\
Observations & Base & Linear & Quadratic & Cubic \\
Mean of Dep. Variable & 43225 & 43225 & 43225 & 43225 \\
\hline
\end{tabular}

Standard errors clustered by commuting zones in parentheses. Specification refers to the order of the polynomial for the running variable, which is distance to the RD boundary. The polynomial is always interacted with the treatment indicator. Sample is all city blocks with zoning information. Mean of dependent variable calculated for control blocks within $0.1 \mathrm{~km}$ of the BAR boundary. ${ }^{*} p<0.05$, ** $p<0.01,{ }^{* * *} p<0.001$. 
Table 3: Supply estimates: Poisson IV regressions

\begin{tabular}{|c|c|c|c|c|c|}
\hline \multirow[t]{2}{*}{ Outcome } & \multicolumn{3}{|c|}{ All new buildings } & \multirow{2}{*}{$\begin{array}{c}\text { Single } \\
(4)\end{array}$} & \multirow{2}{*}{$\begin{array}{c}\text { Multi } \\
\text { (5) }\end{array}$} \\
\hline & (1) & $(2)$ & (3) & & \\
\hline \multirow[t]{2}{*}{ Max BAR } & $0.386^{* * *}$ & $0.789^{* * *}$ & $0.747^{* * *}$ & -0.048 & $0.870^{* * *}$ \\
\hline & $(0.099)$ & $(0.166)$ & $(0.163)$ & $(0.335)$ & $(0.188)$ \\
\hline \multirow[t]{2}{*}{ Price } & $0.140^{* * *}$ & $0.149^{* * * *}$ & $0.415^{* * *}$ & $0.425^{*}$ & $0.387^{* *}$ \\
\hline & $(0.034)$ & $(0.035)$ & $(0.101)$ & $(0.214)$ & $(0.139)$ \\
\hline \multirow[t]{2}{*}{ Density } & 0.222 & 0.116 & -0.292 & -0.176 & -0.251 \\
\hline & $(0.118)$ & $(0.125)$ & $(0.195)$ & $(0.435)$ & $(0.247)$ \\
\hline \multirow[t]{2}{*}{ Age } & $0.017^{*}$ & $0.016^{*}$ & -0.019 & -0.045 & -0.023 \\
\hline & $(0.008)$ & $(0.008)$ & $(0.015)$ & $(0.035)$ & $(0.020)$ \\
\hline \multirow[t]{2}{*}{ Units per building } & -0.005 & -0.006 & -0.013 & -0.025 & $-0.023^{*}$ \\
\hline & $(0.004)$ & $(0.005)$ & $(0.007)$ & $(0.014)$ & $(0.010)$ \\
\hline \multirow[t]{2}{*}{ Historical preservation } & $-0.747^{*}$ & -0.699 & -0.453 & -0.009 & -0.831 \\
\hline & $(0.347)$ & $(0.358)$ & $(0.387)$ & $(0.788)$ & $(0.458)$ \\
\hline$Q$ & $1.764 \mathrm{e}-29$ & $1.658 \mathrm{e}-29$ & $2.684 \mathrm{e}-29$ & $2.712 \mathrm{e}-29$ & $1.007 \mathrm{e}-28$ \\
\hline Observations & 1182 & 1182 & 1182 & 1182 & 1182 \\
\hline IVs & None & $\mathrm{RD}$ & RD, Bartik & RD, Bartik & RD, Bartik \\
\hline
\end{tabular}

Robust standard errors in parentheses. Results are from the estimation of fuzzy regression discontinuity (RD) exponential (Poisson) model, estimated with GMM, on the sample of subprefeitura-quantiles. The RD treatment indicator instruments for Max BAR, while the Bartik labor demand shock instruments for price. All models use an additive error specification to form moment conditions. All specifications include controls for the running variable interacted with the treatment, and the following zoning parameters: maximum shadow ratio, minimum and basic BAR of 2004 and 2016, max BAR of 2004, maximum height, min and max. front setback and maximum area of 2016, (zoning variables averaged within subprefeitura-quantile). $Q$-statistic gives the value of the GMM criterion function at the optimal parameters. The outcome variable is the number of total new building, single-family, or multi-family permit applications between 2016-2019, as indicated. ${ }^{*} p<0.05$, ${ }^{* *} p<0.01,{ }^{* * *} p<0.001$.

Table 4: Estimated demand parameters

\begin{tabular}{|c|c|c|c|c|c|c|c|c|c|}
\hline Demographic & $\begin{array}{l}\text { Price } \\
(1)\end{array}$ & $\begin{array}{c}\text { Travel time } \\
\text { (2) }\end{array}$ & $\begin{array}{c}\text { RCMA } \\
\text { (3) }\end{array}$ & $\begin{array}{l}\text { Age } \\
(4)\end{array}$ & $\begin{array}{l}\text { Units } \\
(5)\end{array}$ & $\begin{array}{c}\text { Density } \\
(6)\end{array}$ & $\begin{array}{l}\text { Paved } \\
\quad(7)\end{array}$ & $\begin{array}{c}\text { Income } \\
(8)\end{array}$ & $\begin{array}{c}\text { Education } \\
\text { (9) }\end{array}$ \\
\hline \multirow[t]{2}{*}{ Household size } & -0.087 & 0.127 & 0.026 & -0.064 & -0.071 & -0.050 & 0.002 & -0.042 & -0.041 \\
\hline & $(0.027)$ & $(0.012)$ & $(0.023)$ & $(0.018)$ & $(0.040)$ & $(0.022)$ & $(0.013)$ & $(0.031)$ & $(0.038)$ \\
\hline \multirow[t]{2}{*}{ Age } & -0.064 & -0.153 & -0.044 & 0.056 & -0.151 & 0.005 & 0.035 & 0.060 & 0.123 \\
\hline & $(0.026)$ & $(0.011)$ & $(0.024)$ & $(0.019)$ & $(0.029)$ & $(0.021)$ & $(0.017)$ & $(0.033)$ & $(0.039)$ \\
\hline \multirow[t]{2}{*}{ Renter } & -0.060 & -0.122 & 0.004 & 0.198 & -0.002 & 0.034 & 0.037 & -0.003 & -0.015 \\
\hline & $(0.026)$ & $(0.011)$ & $(0.022)$ & $(0.019)$ & $(0.027)$ & $(0.018)$ & $(0.017)$ & $(0.032)$ & $(0.036)$ \\
\hline \multirow[t]{2}{*}{ Income } & -0.077 & -0.053 & 0.039 & 0.110 & -0.145 & 0.081 & 0.115 & 0.467 & -0.005 \\
\hline & $(0.034)$ & $(0.023)$ & $(0.033)$ & $(0.036)$ & $(0.060)$ & $(0.024)$ & $(0.046)$ & $(0.041)$ & $(0.058)$ \\
\hline \multirow[t]{2}{*}{ College degree } & -0.185 & -0.047 & -0.017 & -0.011 & -0.163 & 0.068 & 0.058 & -0.314 & 0.880 \\
\hline & $(0.036)$ & $(0.014)$ & $(0.031)$ & $(0.026)$ & $(0.050)$ & $(0.025)$ & $(0.030)$ & $(0.037)$ & $(0.046)$ \\
\hline \multirow[t]{2}{*}{ Base coefficients } & -1.975 & -2.413 & 0.749 & -0.980 & -0.647 & 0.765 & 0.090 & -0.420 & 0.572 \\
\hline & $(0.454)$ & $(0.021)$ & $(0.225)$ & $(0.124)$ & $(0.432)$ & (0.159) & (0.104) & $(0.250)$ & $(0.294)$ \\
\hline
\end{tabular}

Results are from the estimation of demand-side preference parameters using two-step maximum likelihood and 2SLS. Top row gives variable names, while leftmost column gives the demographic variables. Estimation sample is 329 commuting zones and 24,800 individual households. All location characteristics including price are standardized relative to the zone-level sample mean and standard deviation. Travel time is normalized across all individual-zone combinations. Base coefficients are from column (9) of Table A9, which instruments for housing prices using the average spatial and housing characteristics of zones 5-20 miles from a zone centroid. These characteristics are favela share of zone area, slope, RCMA, and housing stock age. Bootstrapped standard errors with 500 replications in parentheses. 
Table 5: Simulation results: prices and quantities

\begin{tabular}{|c|c|c|c|}
\hline Scenario & 2004 zoning & 2016 zoning & Double BAR \\
\hline Max BAR & 1.55 & 2.09 & 3.49 \\
\hline \multicolumn{4}{|c|}{ Panel A: Equating shares } \\
\hline New units (ths) & 166.357 & 213.387 & 844.607 \\
\hline New units (share of stock) & 0.068 & 0.087 & 0.343 \\
\hline Avg. price (ths of reales) & 6.114 & 6.083 & 5.655 \\
\hline Inside share & 0.587 & 0.591 & 0.637 \\
\hline \multicolumn{4}{|c|}{ Panel B: Equating levels } \\
\hline New units (ths) & 157.931 & 199.714 & 667.027 \\
\hline New units (share of stock) & 0.064 & 0.081 & 0.271 \\
\hline Avg. price (ths of reales) & 5.987 & 5.922 & 5.060 \\
\hline Inside share & 0.606 & 0.615 & 0.713 \\
\hline
\end{tabular}

Table shows zone-level results from equilibrium simulations under three different zoning scenarios, as indicated in table header. Double BAR scenario holds BAR constant at 2004 levels for all locations where BAR was reduced in 2016, and doubles the post-2016 BAR value in all locations where BAR was increased in 2016. First row shows average block-level maximum allowable BAR under each scenario. Panel A equates market shares in the equilibrium condition, implicitly assuming that all new construction within the city is occupied by new migrants from outside the MSA. Panel B equates levels in the equilibrium condition, implicitly assuming that all new construction in the city is occupied by migrants from the outside the city but within the MSA. Average price is thousands of reales per square meter. Inside share is fraction of households living within the municipality. Avg. zone income is in thousands of reales per household per year. Avg. zone education is fraction of households with a college degree. 
Table 6: 2026 Simulation results: individual-level consumer surplus

\begin{tabular}{|c|c|c|c|c|c|c|}
\hline \multirow{2}{*}{$\begin{array}{l}\text { Scenario } \\
\text { Update }\end{array}$} & \multicolumn{3}{|c|}{2016 zoning } & \multicolumn{3}{|c|}{ Double BAR } \\
\hline & $P$ & $X$ & $\tau$ & $P$ & $X$ & $\tau$ \\
\hline & $(1)$ & $(2)$ & (3) & (4) & (5) & (6) \\
\hline \multicolumn{7}{|l|}{ By demographic group } \\
\hline Owner & 25.08 & 115.94 & 114.54 & 330.01 & 2301.52 & 2243.39 \\
\hline Renter & 26.55 & 86.04 & 84.47 & 388.08 & 1847.74 & 1792.12 \\
\hline Non-college & 21.59 & 94.18 & 92.98 & 287.48 & 1908.11 & 1855.33 \\
\hline College & 39.56 & 160.68 & 158.36 & 553.04 & 3211.69 & 3136.94 \\
\hline \multicolumn{7}{|l|}{ By income quintile } \\
\hline 1 & 19.69 & 86.06 & 84.99 & 263.88 & 1785.35 & 1734.99 \\
\hline 2 & 21.31 & 94.76 & 93.52 & 280.45 & 1878.78 & 1826.89 \\
\hline 3 & 23.38 & 102.18 & 100.85 & 314.09 & 2066.02 & 2010.61 \\
\hline 4 & 27.33 & 117.97 & 116.40 & 372.71 & 2368.84 & 2307.52 \\
\hline 5 & 36.15 & 143.77 & 141.72 & 500.54 & 2886.96 & 2817.60 \\
\hline \multicolumn{7}{|l|}{ Totals } \\
\hline Full sample & 25.45 & 108.46 & 107.02 & 344.52 & 2188.10 & 2130.60 \\
\hline Aggregate consumer surplus (mm reales) & 136.44 & 581.56 & 573.82 & 1847.25 & 11732.12 & 11423.82 \\
\hline
\end{tabular}

Table shows per-household expected change in consumer surplus from equilibrium simulation of the 2016 zoning reform and Double BAR reform for different subgroups, measured in Brazilian reais. Bottom row shows the total consumer surplus aggregating across all households in millions of reais. Columns (1) and (3) update only equilibrium prices from the 2016 reform scenario, while columns (2) and (4) update both prices and the housing and neighborhood attributes included in $X_{j}$. Columns (3) and (6) update all variables, including travel time $\tau$. All changes are evaluated relative to 2004 (status quo) zoning.

Table 7: Comparison of 2026 welfare estimates and other policy effects

\begin{tabular}{lcccccc}
\hline \hline \multirow{2}{*}{ Scenario } & \multicolumn{2}{c}{ 2016 Reform } & & \multicolumn{2}{c}{ Double BAR } \\
\cline { 2 - 3 } \cline { 6 - 7 } Units & R\$ bi & \% of GDP & & R \$ bi & \% of GDP \\
\hline Change in welfare & 0.57 & 0.08 & & 11.42 & 1.63 \\
Change in value - homeowners & -9.88 & -1.41 & & -123.57 & -17.65 \\
Change in value - landlords & -3.29 & -0.47 & & -44.90 & -6.41 \\
Change in developer profits & 3.96 & 0.57 & & 52.38 & 7.48 \\
New resident welfare gains & 0.0051 & 0.001 & & 1.45 & 0.21 \\
Change in productivity & 0.80 & 0.11 & & 11.56 & 1.65 \\
\hline
\end{tabular}

Table shows calculations for policy effects on consumer welfare, housing wealth, and developers' profits, from equilibrium simulations under two different zoning scenarios, as indicated in table header. Double BAR scenario holds BAR constant at 2004 levels for all locations where BAR was reduced in 2016, and doubles the post-2016 BAR value in all locations where BAR was increased in 2016. All gains and losses are evaluated relative to the 2004 status quo simulation. Developers are assumed a 10\% profit margin on total housing revenues. Homeowners refers to value of all owned-occupied units, landlords refers to value of all rental units. GDP refers to 2017 total output of Sao Paulo city. All simulations equate market shares in the equilibrium condition, implicitly assuming that all new construction within the city is occupied by new migrants from outside the MSA. 